Portland State University

PDXScholar

4-29-1994

\title{
Extracellular Matrix Proteins of the Nurse Cell Capsule in Trichinella spiralis Infections
}

Mary Louise Taylor

Portland State University

Follow this and additional works at: https://pdxscholar.library.pdx.edu/open_access_etds

Part of the Biology Commons

Let us know how access to this document benefits you.

Recommended Citation

Taylor, Mary Louise, "Extracellular Matrix Proteins of the Nurse Cell Capsule in Trichinella spiralis Infections" (1994). Dissertations and Theses. Paper 4782.

https://doi.org/10.15760/etd.6666

This Thesis is brought to you for free and open access. It has been accepted for inclusion in Dissertations and Theses by an authorized administrator of PDXScholar. Please contact us if we can make this document more accessible: pdxscholar@pdx.edu. 
THESIS APPROVAL

The abstract and thesis of Mary Louise Taylor for the Master of Science degree in Biology were presented Apri1 29, 1994 and accepted by the thesis

committee and the department.

COMMITTEE APPROVALS:

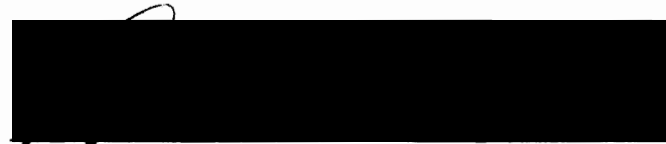
David T. Clark Chair
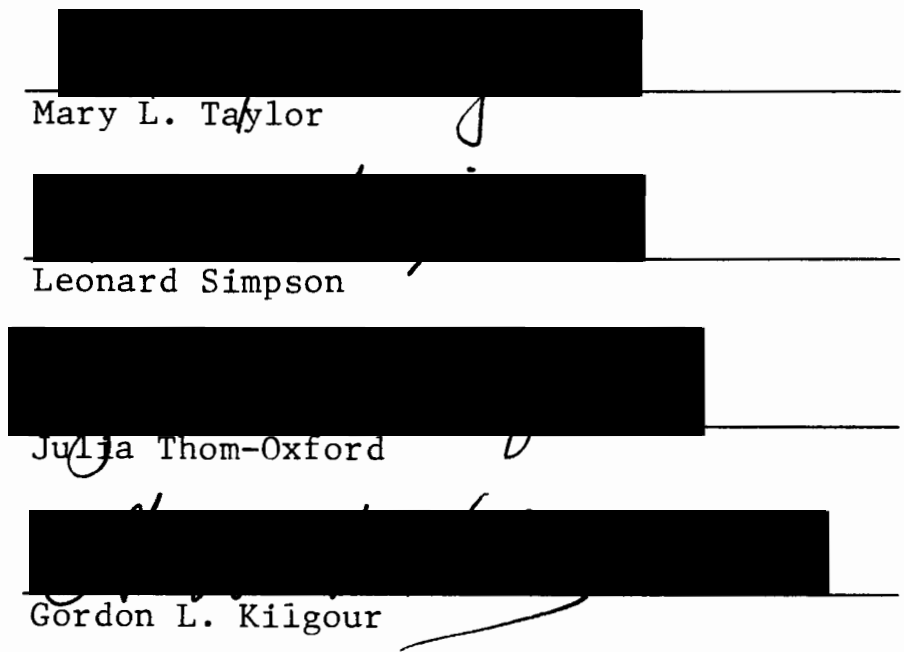

Representative of the Office of Graduate Studies

DEPARTMENT APPROVAL:



Robert 0 . Tinnin, Chair

Department of Biology

\section{ACCEPTED FOR PORTLAND STATE UNIVERSITY BY THE LIBRARY}

by

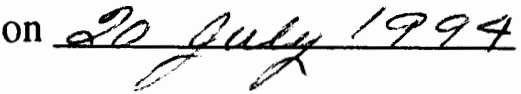




\begin{abstract}
An abstract of the thesis of Mary Louise Taylor for the Master of Science in Biology presented April 29, 1994.

Title: Extracellular Matrix Proteins of the Nurse Cell Capsule in Trichinella spiralis Infections.
\end{abstract}

The infectious first-stage larvae of the nematode Trichinella spiralis is an intracellular parasite of altered skeletal muscle. Invasion of the muscle cell initiates a series of morphological changes in the host muscle cell which ultimately results in a specialized unit called the nurse cell. The completed nurse cell consists of a collagenous capsule, matrix of altered sarcoplasm, and a circulatory rete.

The purpose of this study was to determine the types of collagen present in the nurse cell capsule. Additionally, the presence of the glycoproteins, laminin and tenascin was determined. This study also sought to demonstrate the location of the selected extracellular matrix proteins within the capsule.

Nurse cells were isolated from infected host muscle by sequential protease treatment with pronase, collagenase, and hyaluronidase. Nurse cells were digested with pepsin to produce characteristic pepsin-resistant triple helical fragments of collagen. The nurse cellpepsin digest was characterized by SDS-page, under reduced and nonreduced conditions, with type VI collagen and the $\alpha 1 \alpha 2 \alpha 3$ chains of type XI collagen.

Frozen tissue sections of infected and non-infected rat diaphragms were screened with specific polyclonal antibodies against types I, III, IV, V/XI, and VI collagen, laminin, and 
tenascin. Indirect immunofluorescence using FITC secondary antibodies was used to locate the protein in the capsule and host tissue.

SDS-page of the nurse cell-pepsin digest produced an electrophoretic pattern of resistant fragments characteristic for types I, III, IV, V, and VI collagen. Additionally, fragments migrated with an apparent molecular weight expected for pepsin resistant fragments of laminin. Indirect immunofluorescence showed types I, III, IV, and VI collagen, and laminin were distributed throughout the capsule. Serum No. 4876, which recognizes type V/XI collagen, localized to the larvae. Tenascin failed to stain the nurse cell or host tissue.

The results show that the capsule is a heterogenic structure with types I, III, IV, V, and VI collagens, and laminin distributed throughout the structure. The immunolocalization of Serum No. 4876 to the larvae suggests that a nematode collagen shares an amino acid sequence in common with mammalian type V/XI collagen. 


\title{
EXTRACELLULAR MATRIX PROTEINS OF THE NURSE CELL CAPSULE IN TRICHINELLA SPIRALIS INFECTIONS
}

\author{
by \\ MARY LOUISE TAYLOR
}

A thesis submitted in partial fulfillment of the requirements for the degree of

MASTER OF SCIENCE
in
BIOLOGY

Portland State University 1994 


\section{ACKNOWLEDGEMENTS}

I am indebted to the members of the Research Unit, Shriner's Hospital for Crippled Children, Portland, Oregon. Their kind support enabled this research project to be completed. They were generous with technical advice, materials, and resources. In particular, I wish to thank the following members of the Research Unit: Drs. Julia ThomOxford and Nicholas Morris, Barbara Smoody, Doug Keene, and Cathy Ridgeway.

A great debt is owed to Dr. Julia Thom-Oxford and Dr. Nicholas Morris for their encouragement and expert technical advice during this project. I thank them for their permission to work in their laboratory and use their equipment including the cryostat, fluorescent microscope and camera, and SDS-page apparatus. I also wish to express my appreciation to both Dr. Thom-Oxford and Barbara Smoody for their instruction in laboratory techniques. I learned an enormous amount from observing their work and asking questions. Thank you!

I wish to thank Laboratory Four of the Research Unit for their kind gifts: pepsin, collagenase, and hyaluronidase; type VI collagen, the $\alpha 1 \alpha 2 \alpha 3$ marker of type XI collagen, Biorad prestained molecular weight markers; the polyclonal antibodies: Serum No. 4876, Serum No. 4104-Bound, and Serum No. 4104-Unbound; and FITC-conjugated secondary antibodies.

My thanks also extend to Doug Keene and Cathy Ridgeway, Electron Microscopy, for their electron microscopy work, the production of the electron micrographs, and the opportunity to sit at the electron microscope. I also wish to thank Mr. Keene for introducing my project to his fellow microscopist, Ken Tiekotter of Good Samaritan Hospital, who also has a great interest in parasitology. My thanks also extend to Ken 
Tiekotter, who not only produced electron micrographs for this project, but also demonstrated the operation of the electron microscope. Thank you, everyone, for the wonderful electron micrographs and the demonstrations.

I wish to thank Dr. Elaine Johnson of the Casey Eye Institute, Portland, for her kind assistance and gifts of polyclonal antibodies. Thank you, Dr. Johnson, for showing me methods of preserving frozen tissue samples and for training me in the operation of the cryostat. Additionally, I wish to thank Dr. Johnson, Lisa Deppmeier, and Susan for their advice regarding antibodies and the opportunity to try immunohistochemistry.

I also wish to thank, Anonymous, Gibco BRL, who generously sent me antibodies against type III collagen, type VI collagen, and laminin for trial use in this project. My thanks also extend to Southern Biotechnology Associates for sending me samples of their polyclonal antibodies free-of-charge. I am extremely grateful for their consideration.

My thanks go to the members of the Thesis Committee: Drs. David Clark, Mary Taylor, Leonard Simpson, Gordon Kilgour, and Julia Thom-Oxford. They have made time available to review and critique this document. I also wish to thank Dr. Peter Paquet, who kindly reviewed this thesis.

Finally, I wish to thank my husband, Ian Taylor, for his support and tolerance during the pursuit of a Master's degree. He has supported my decision, even though it has required liquidation of several of my personal assets to pay for classes, child care, and to subsidize the thesis project.

My sincere appreciation extends to all of you for making it happen. Your generosity will not be forgotten. 


\section{TABLE OF CONTENTS}

PAGE

ACKNOWLEDGEMENTS $\ldots \ldots \ldots \ldots \ldots \ldots \ldots \ldots \ldots$ iii

LIST OF TABLES $\ldots \ldots \ldots \ldots \ldots \ldots \ldots \ldots \ldots \ldots \ldots \ldots \ldots \ldots \ldots \ldots \ldots$

LIST OF FIGURES $\ldots \ldots \ldots \ldots \ldots \ldots \ldots \ldots \ldots \ldots \ldots \ldots \ldots \ldots$ vii

INTRODUCTION $\ldots \ldots \ldots \ldots \ldots \ldots \ldots \ldots \ldots \ldots \ldots \ldots \ldots \ldots \ldots \ldots$

The Parasite . . . . . . . . . . . . . . . 1

The Lifecycle Of Trichinella spiralis $\ldots \ldots \ldots \ldots \ldots \ldots \ldots \ldots$

Research Objective $\ldots \ldots \ldots \ldots \ldots \ldots \ldots \ldots \ldots \ldots \ldots$

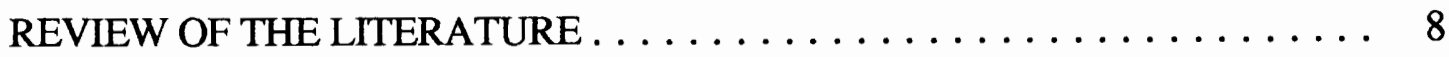

Muscle Stage Of The Infection . . . . . . . . . . 8

Parasite Entry

Muscle Cell Transformation Into Nurse Cell

Nurse Cell Capsule Formation

Nurse Cell Structure

Extracellular Matrix Proteins $\ldots \ldots \ldots \ldots \ldots \ldots \ldots \ldots \ldots \ldots$

Collagen

Glycoproteins

Normal Muscle

The Basis For Pepsin Digestion . . . . . . . . . . . . . . 21

Electrophoretic Properties

Isolation And Analysis Of Intact Nurse Cells

MATERIALS AND METHODS $\ldots \ldots \ldots \ldots \ldots \ldots \ldots \ldots \ldots \ldots \ldots$

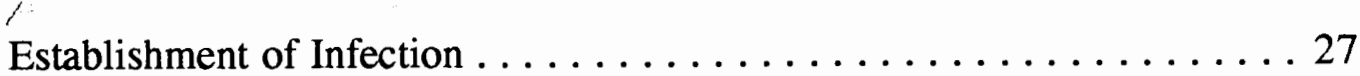

Animals 
Analysis of Nurse Cells . . . . . . . . . . . . . . . 27

Isolation Of Nurse Cells

Pepsin Digestion of Nurse Cells

SDS-page Electrophoresis

Microscopy ........................... 31

Electron Microscopy

Frozen Tissue Embedding

Indirect Immunofluorescence

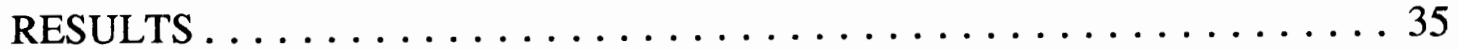

Electron Microscopy . . . . . . . . . . . . . . . . . 35

SDS-page Analysis $\ldots \ldots \ldots \ldots \ldots \ldots \ldots \ldots \ldots \ldots \ldots \ldots \ldots \ldots \ldots \ldots$

Indirect Immunofluorescence Pattern $\ldots \ldots \ldots \ldots \ldots \ldots \ldots \ldots . \ldots . \ldots$.



Nurse Cell Capsule . . . . . . . . . . . . . . . . 51

Type V/XI Collagen

Tenascin

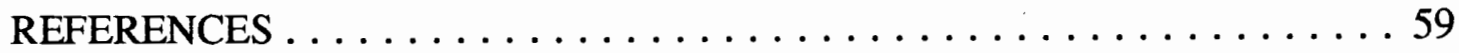




\section{LIST OF TABIES}

\section{TABLE}

PAGE

I Summary Of Nurse Cell Pepsin Resistant Fragments Characterized By SDS-page . ................... 41

II Tissue Localization of Extracellular Matrix Proteins In Normal

And Infected Hosts Using Indirect Immunofluorescence . . . 43 


\section{LIST OF FIGURES}

FIGURE

PAGE

1. Electron Micrograph Of The Nurse Cell-Parasite Complex ..... . 5

2. Electron Micrograph Of Assumed Secretion Granules Within

A Stichosome Of An Infective L1 Larva .......... 11

3. Electron Micrograph Of The Nurse Cell Capsule ......... 15

4. High Power Electron Micrograph Of The Nurse Cell Capsule ... . 36

5. Electron Micrograph Of Infective Muscle Stage L1 . . . . . 37

6. Characterization Of The Collagens Of The Nurse Cell Capsule

By SDS-page Of Pepsin Resistant Fragments in a 8.5\%

Reduced Gel .................... 39

7. Immunolocalization Of Types I And III Collagen In

Nurse Cells And Non-infected Muscle . . . . . . . . 47

8. Immunolocalization Of Type IV Collagen and Laminin In

Nurse Cells And Non-infected Muscle . . . . . . . . . 48 
9. Immunolocalization Of Type VI Collagen In Nurse Cells

And Non-infected Muscle . . . . . . . . . . . . . . 49

10. Immunolocalization Of Type V/XI Collagen, Tenascin, And

Negative Controls In Nurse Cells And Non-infected Muscle . . 50 


\section{INTRODUCTION}

\section{THE PARASITE}

Trichinella spiralis is one of several parasitic nematodes of economic and clinical importance which occur within the phylum Nematoda, class Amphasmidia, order Trichurata, family Trichinellidae (Schmidt and Roberts 1989). Trichinella spiralis is cosmopolitan in distribution and widespread among carnivores, including representative hosts from all orders except Insectivora (Campbell 1983). Its sibling species include: Trichinella nelsoni, a tropical form; Trichinella pseudospiralis which is Nearctic; and Trichinella nativa which is arctic in distribution (Pozio, La Rosa and Rossi 1989). Trichinella pseudospiralis differs from other species in its genus because it is a noncystforming species (Marinculic et al. 1991).

Trichinella spiralis is responsible for the clinical disease known as trichinosis. Most mammals, including wild and domestic animals and humans, are susceptible to infection. The disease cycle of greatest epidemiological importance is urban trichinosis. Urban trichinosis is the transmission of the parasite through the domestic food chain from infected rats and pigs to humans.

Sylvatic trichinosis occurs between wild animals during predation and scavenging upon infected prey or carrion. This disease cycle is rarely a problem in modern society unless individuals participate in the sylvatic food chain through the consumption of wild meat, especially the meat of wild carnivores. 
THE LIFECYCLE OF TRICHINELLA SPIRALIS

The lifecycle of Trichinella spiralis is representative of other member species in the family Trichinellidae, except for Trichinella pseudospiralis. The lack of complete cyst formation is characteristic for Trichinella pseudospiralis which is a parasite of birds and mammals (Despommier 1993). Trichinella pseudospiralis does not elicit an inflammatory response around its infected host muscle cells suggesting suppression of the host inflammatory response to muscle-stage larvae (Larsen et al. 1991).

Trichinella spiralis has a unique host-parasite relationship. It is unusual in that the definitive and intermediate host are the same animal, with adult and juvenile worms occupying separate organs (Schmidt and Roberts 1989). Within each susceptible mammalian host, the parasite lives most of its life intracellularly (Despommier 1983).

Trichinella spiralis is adapted to life in the intracellular environment of altered striated skeletal muscle cells for an extended period as first stage infective larvae (L1) (Purkerson and Despommier 1974). It occupies this intracellular niche without ultimately destroying the host muscle cell in the process, despite the fact that it is a large parasite approximately 900-1000 $\mu \mathrm{m}$ long (Despommier 1990, Jasmer 1990, Schmidt and Roberts 1989).

For the purpose of discussion, the lifecycle begins when infectious muscle encysted L1 are consumed in contaminated and raw or undercooked meat (Schmidt and Roberts 1989). During the process of digestion, the host connective tissue, infected muscle, and the nurse cell capsule surrounding the L1 are mechanically and enzymatically removed (Stewart and Giannini 1982).

The liberated L1 pass into the lumen of the small intestine where they penetrate the columnar epithelial cells within ten minutes (Despommier et al. 1978). The L1 rapidly progress through four molts, becoming the larval stages $\mathrm{L} 2, \mathrm{~L} 3$, and $\mathrm{L} 4$ and reach adulthood within 30 to 32 hours (Schmidt and Roberts 1989). The L1 molts at approximately 8 hours post-infection, the L2 molts at approximately 13 hours, the L3 molts 
at approximately 16-17 hours, and the final molt, which transforms the L4 into an adult, occurs at approximately 26-31 hours (Kozek 1971).

When sexually mature, the adults mate while located within the cytoplasm of an intramulticellular niche consisting of a serial row of intestinal cells (Wright 1979). While the male dies shortly after copulation, the female begins to shed newborn larvae into the cell within five to seven days (Chandler and Read 1964, Vassilatis et al. 1992). Over a period of 4 to 16 weeks, the female sheds approximately 1500 newborn larvae and then dies (Schmidt and Roberts 1989, Chandler and Read 1964, Despommier 1993). Ultimately, the parasitized intestinal cells are destroyed due to damage from the nematode (Wright et al. 1987).

Most of the newborn larvae migrate away from the intestinal mucosa through the bloodstream via the hepatic portal circulation (Wang and Bell 1986) and not the lymphatic system as previously believed (Despommier 1976). Scintigraphic studies show most of the newborn larvae pass through the lungs where cuticular proteins are detached and retained (Bruschi et al. 1992). These modifications to the cuticle may increase resistance to host nonspecific defense mechanisms and enhance the parasite's ability to mount a muscle stage infection. Their findings suggest that newborn larvae take only a few minutes to pass through the lungs.

The arterial system transports the larvae passively to their ultimate destination: striated skeletal muscle. During migration, the larvae may enter a variety of host cell types but they complete their development only within skeletal muscle (Despommier 1990). The transit time of newborn larvae from the lungs to the chosen skeletal muscle may be only fifteen minutes (Bruschi et al. 1992).

The larvae penetrate individual muscle fibers and migrate away from the site of entry to a more remote section of the musle cell (Stewart and Giannini 1982). Within their intracellular niche, the larvae grow and mature over a period of approximately twenty days 
into fully infective first stage larvae (L1) (Despommier et al. 1975). There are no intramuscular molts by L1 (Kozek 1971). This completes the parasite's lifecycle.

Concurrently, the infected muscle cell undergoes morphological and biochemical modifications that transform it into a specialized unit, called the nurse cell. Figure 1 shows an electron micrograph of a nurse cell-parasite complex within an infected mouse diaphragm.

The nurse cell provides a favorable environment and sustains the parasite through the life of the mammalian host (Despommier 1975, Vassilatis et al, 1992). The nurse cell also provides protection during transmission of the infection during predation or scavenging upon infected hosts (Despommier 1990).

The nurse cell, as discussed in Despommier (1993) is characterized by a fibrous capsule which surrounds a portion of modified skeletal muscle in which the $L 1$ reside. The entire nurse cell-parasite complex is surrounded by a circulatory rete. The term nurse cell has frequently been used based on the belief that it provides, and later, transports nutrients necessary for larval growth, development, and homeostasis during the L1 larval stage of the nematode's life cycle (Jasmer 1990, Stewart and Giannini 1982, Purkerson and Despommier 1974). Subsequently, analogies have been made regarding the nurse cell's performance as a placenta (Despommier 1990).

The terminology as stated in Bruce (1970) and Teppema et al. (1973) is frequently used to describe nurse cell structure. In this thesis, "capsule" refers to the compacted fibrous area which surrounds the "matrix", the term given to the portion of altered host muscle sarcoplasm in which the parasite resides.

The capsule's ultrastructural character has been analyzed by both electron microscopy and light microscopy using histochemical techniques (Teppema et al. 1973, Bruce 1970). The exact composition and formation of the capsule has not been determined. 


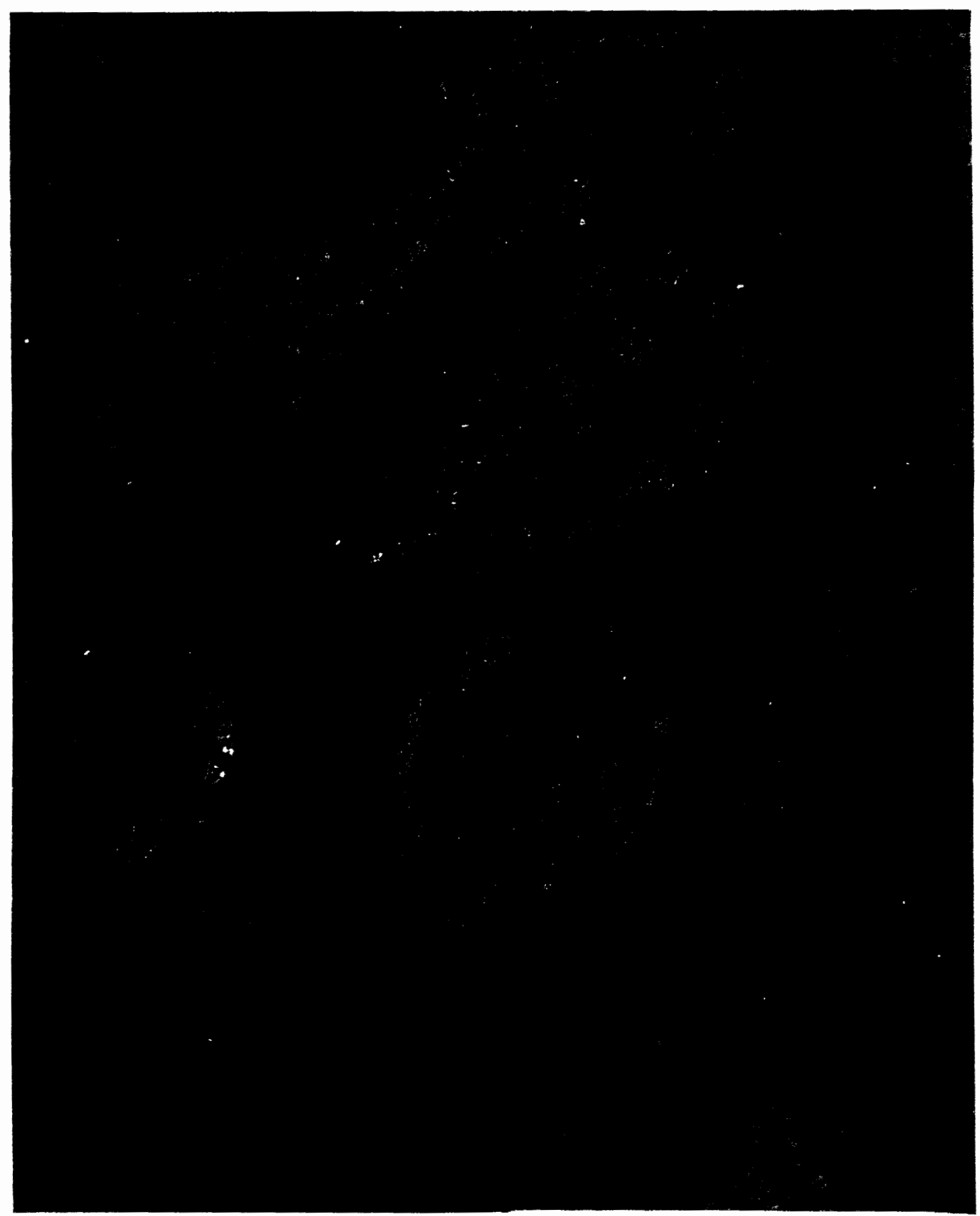

Figure 1. Electron micrograph of the nurse cell-narasite complex. Infective I I (L1) lie within altered host muscle sarcoplasm called the matrix (M). A fibrous capsule (C), composed of layers of collagen and possibly other extracellular matrix proteins, surrounds the matrix and L1. Host endomysium $(\mathrm{H})$. Magnification, $1,179 \mathrm{x}$, bar $=8480 \mathrm{~nm}$. 
Bruce (1970) characterized the capsule as being composed of two collagenous regions, an outer region of many compacted fibrils, and an inner region that was more amorphous. In histochemical studies, Bruce (1970) found the capsule to be glycogen rich, Periodic Acid Schiff (P.A.S.) positive, positive for collagen, and high in cystine content. The capsule also stained positive for nonspecific esterase.

\section{RESEARCH OBJECTIVE}

Piez and Reddi (1984) describe the extracellular matrix as all material outside of cells and inside the epithelial and endothelial boundaries of multicellular animals. Furthermore, the extracellular matrix includes proteins and other macromolecules associated specifically with cell surfaces but not embedded in the plasma membrane. The major classes of macromolecules which comprise the extracellular matrix are the collagens, proteoglycans, glycoproteins, and elastin (Hay 1981).

Extracellular matrix proteins have a specificity with respect to their distribution among tissues and also their localization within a tissue. For example, laminin and type IV collagen are components of basement membranes (Panayotou et al. 1989) while type II collagen is restricted to cartilage (Morris et al. 1990).

The purpose of this study is to determine which members of the family of collagens are present in the nurse cell capsule. The class of collagen, present within the nurse cell capsule, will be determined through the use of standard methods of detection of pepsin resistant triple-helical fragments. These fragments will be characterized by sodium dodecyl sulfate polyacrylamide gel electrophoresis (SDS-page) and compared to authentic $\alpha 1 \alpha 2 \alpha 3$ chains of type XI collagen and type VI collagen which serve as standards of the apparent molecular weight of collagens. The localization, within the nurse cell capsule, of extracellular matrix proteins, will be determined by polyclonal antibody detection using indirect immunofluorescence. 
I hypothesize that there are several collagen types present in the capsule, as well as structural glycoproteins such as laminin. An examination of the extracellular matrix proteins found in the nurse cell capsule may provide information on the capsule's function in maintaining a suitable microenvironment for the $\mathrm{L} 1$ larva. It may also provide information regarding the formation of the capsule. 


\section{REVIEW OF THE LITERATURE}

\section{MUSCLE STAGE OF THE INFECTION}

\section{Parasite Entry}

First-stage migratory larvae (L1) enter host muscle cells from the arterial circulation (Wang and Bell 1986) and preferentially infect highly active muscles with rich blood supplies (Stewart and Giannini 1982). Actual selection of a muscle may depend on the parasite's positive taxis to the $120-\mathrm{mV}$ action potential of striated muscle and/or the increased negativity of the sarcolemma of highly active muscles (Hughes and Harley 1977). Examples of muscles which become heavily infected are: diaphragm, tongue, masseter and the large muscles of the limbs.

The migratory L1 attach to the sarcolemma of a striated myofiber causing an indentation in this structure (Stewart and Giannini 1982). Penetration of the host muscle cell is accomplished by a mechanical process and results in a gaping tear of the sarcolemma (Despommier 1976).

Once inside the muscle, the L1 migrate away from the point of entry to a more remote portion of the cell. They travel beneath the sarcolemma and create an open tunnel in their wake which eventually closes, thus isolating them inside an intracellular environment. Migration causes disruption of contractile filaments in the immediate vicinity of the worm (Despommier 1975).

Teppema et al. (1973) describes a local inflammatory reaction around infected muscle fibers which decreases over time. Their analysis by electron microscopy indicates the presence of eosinophils, macrophages, mononcytes, lymphocytes, plasma cells and giant cells in the inflamed area. Some of the infiltrating cells can be found within the host 
sarcoplasm. Fibroblasts were not thought to be prominent in the local area, even during development of the capsule (Teppema et al. 1973).

Stewart et al. (1972) also describes an inflammatory reaction around the infected muscle. On day 10 post-infection, there is an absence of myositis but evidence of myofibrillar disorganization. Myositis is evident on day 13 and worsens to severe myositis by day 25 post-infection. They note the presence of eosinophils, neutrophils, and an increase in peroxidase activity. Myositis declines slightly by day 30 post-infection. Once the capsule is fully developed, the effect of inflammatory cells on the L1 is minimal (Cheville 1988, Wassom 1993).

\section{Muscle Cell Transformation Into Nurse Cell}

Invasion of the muscle cell initiates a complex series of morphological changes in both the parasite and host muscle cell which ultimately results in a specialized unit called the nurse cell (Purkerson and Despommier 1974). The L1 undergo a maturation process, concurrently with nurse cell development, which results in a fully infective state. These events take approximately 20 days from the time of muscle cell penetration to the completion of the nurse cell-parasite complex (Despommier et al. 1975, Despommier 1990, Jasmer 1990, Despommier 1993).

Despommier (1990) provides a summary of the main events which characterize the transformation of muscle cell to nurse cell. There is production of a thick collagenous outer coat which encloses the L1 within altered host sarcoplasm (Bruce 1970, Ritterson 1966, Despommier 1975, and Teppema et al. 1973). Angiogenesis occurs resulting in the production of a circulatory rete around the nurse cell-parasite complex (Baruch and Despommier 1991).

Within the altered host muscle sarcoplasm, there is an increase in number and enlargement of nuclei with prominent well-defined nucleoli (Despommier 1975). There is 
an average of 40 nuclei per nurse cell (Despommier et al. 1991). The enlarged nuclei are considered to be derived from myogenic and satellite cell nuclei (Stewart 1983). However, Jasmer (1993) presents evidence that suggests infected cell nuclei are derived from the differentiated muscle cell nuclei present at the time of muscle penetration. Satellite cells are muscle stem cell precursors which, when activated, provide a new cell population for muscle regeneration (Yamada et al. 1989).

During development of the nurse cell, and for at least six months after, secreted larval antigens localize to the cytoplasm and hypertrophic nuclei in each nurse cell (Lee et al. 1991, Despommier et al. 1990). The larvae synthesize and store secretion granules in the cells of the stichosome, an exocrine organ located near the esophagus (Takahashi et al. 1992). Figure 2 shows an electron micrograph of assumed secretion granules within a larval stichosome (based on morphological similarities to published electron micrographs Takahashi et al. 1992).

Larval antigens localize to the nucleoplasm and cytoplasm of infected muscle cells by day 9 post-penetration (Despommier et al. 1990). Consequently, it has been suggested that the excretory/secretory products of the L1 play a part in the transformation of the muscle cell to nurse cell (Lee and Shivers 1987, Lee et al. 1991, Ko et al. 1992) and may control the genomic expression of the host. Despommier (1990) suggests that secreted larval antigens may be implicated in the maintenance of the nurse cell-parasite complex.

However, the recent experiments of Jasmer (1993) show that the nurse cell nuclei incorporate $[3 \mathrm{H}]$ thymidine from 2-5 days post muscle penetration. Parasite antigens have not been detected in the nucleus before day 7 post muscle penetration (Despommier et al. 1990, Jasmer 1993). Therefore, Jasmer (1993) suggests that other host and/or parasite factors, such as host inflammatory cells, may induce the changes in phenotype seen in the parasitized muscle cell. Jasmer (1993) also shows that nurse cell nuclei are induced to 


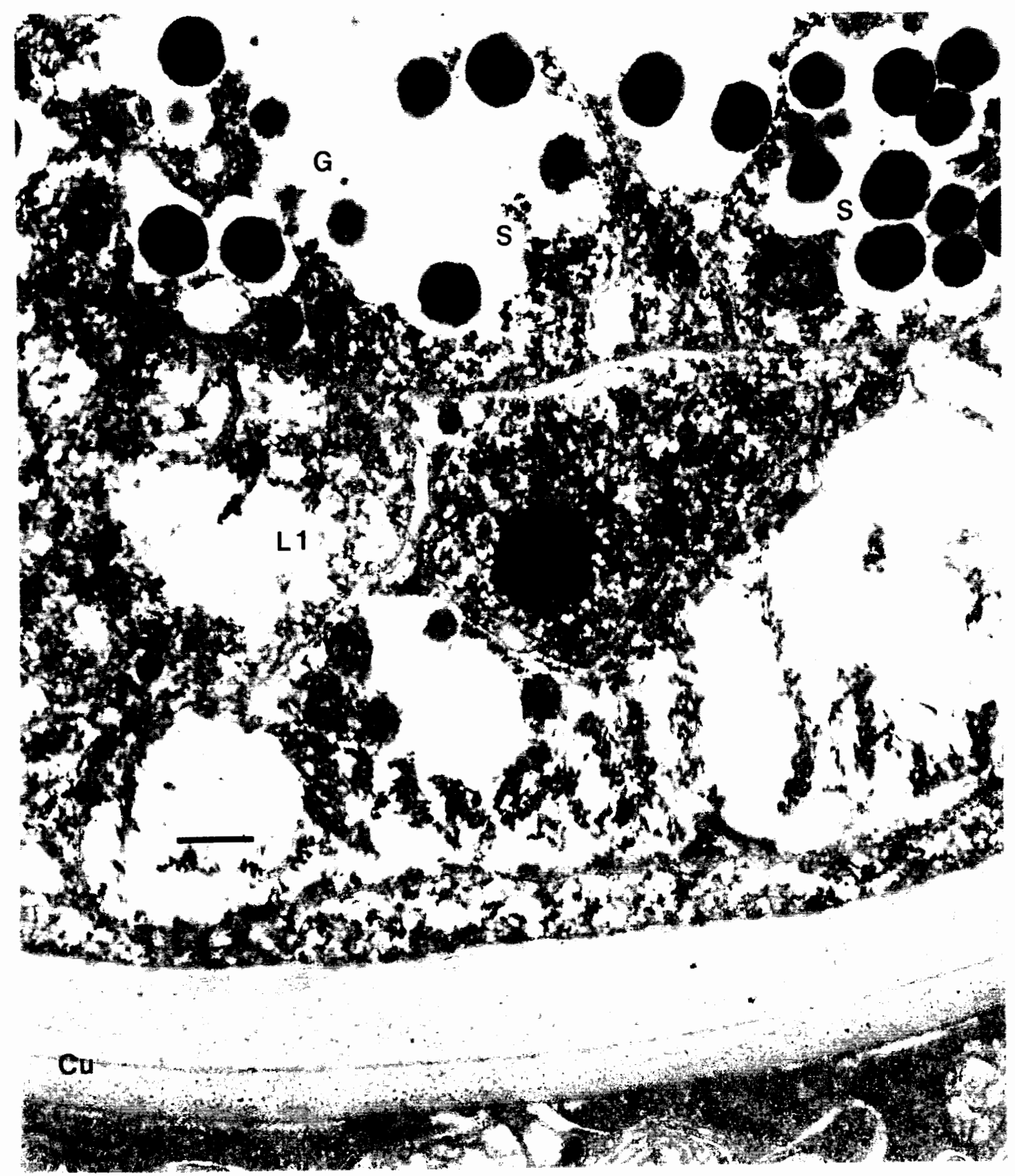

Figure 2. Electron micrograph of assumed secretion granules within a stichosome of an infective L1 larva (L1). Stichocyte (S) granules (G) gather in clusters around the esophagus for secretion. Cuticle $(\mathrm{Cu})$, Matrix of altered sarcoplasm (M).

Magnification, 27,248× , bar $=370 \mathrm{~nm}$. 
maintain a $4 \mathrm{~N}$ complement of DNA and are suspended in the cell cycle at G2/M and cease muscle gene expression.

Within the parasitized muscle cell, there is dissolution and loss of myofibrils and a decrease in myofibrillar and other muscle proteins (Stewart and Read 1974, Jasmer 1990). Myofibrils are replaced with whorls of smooth membranes and partially dysfunctional mitochondria (Despommier 1975). Ultrastructural studies indicate that there is an abundance of organelles within the sarcoplasm of the parasitized muscle cell (Purkerson and Despommier 1974, Despommier 1975).

The increase in the number of organelles, which is associated with protein synthesis and its related functions, has led to speculation that infected muscle cells express a regenerating phenotype (Stewart and Read 1972 a, b, 1973 a, b). There theory has been modified to characterize the process as redifferentiation into an entirely new type of cell (Stewart and Read 1974, Stewart 1983).

However, Jasmer (1993) and Vassilatis et al. (1992) present evidence that the process of transformation from muscle cell to nurse cell could be interpreted as a dedifferentiation event. Jasmer (1993) shows that the nurse cell nuclei are unable to express the myogenic program and that infected cells have elevated levels of the protein Id, which is a negative helix-loop-helix muscle transcriptional regulatory factor, and decreased levels of the muscle transcriptional regulators myogenin and MyoD1. Vassilatis et al. (1992) also suggests that a 43-kDa glycoprotein secreted from the larvae has a potential helix-loop-helix motif which has some homology with the amino acid sequence of the protein Id and may function in the modulation of gene expression in the infected cell.

These changes within the muscle cell result in a structure, the nurse cell, which has a high degree of chemical and structural stability and is more favorable for L1 larval growth and development (Stewart and Giannini 1982). The removal of structural elements, such as myofibrils, and chemicals supportive of muscle contraction eliminates changes in energy, 
$\mathrm{pH}$, and ionic levels associated with muscle contraction (Stewart and Giannini 1982). Additionally, the capsule surrounding the nurse cell's altered sarcoplasm and L1 may offer protection from host immune attack (Cheville 1988, Wassom 1993). Finally, the nurse cell structure supports the nutrition of the larva and handling of waste products (Teppema et al. 1973).

The importance of the nurse cell-parasite complex, in Trichinella spiralis infections is evident from the following. First, the nurse cell remains alive, in most instances, for the life of the host (Trager 1986, Despommier 1990). Secondly, there is no reported instance of mature L1 living freely in the cell (Despommier et al. 1991). Thirdly, there are no reports of nurse cells occurring without a living L1 parasite (Despommier et al. 1991). For example, selective treatment of the infection with anthelmintics, such as mebendazole (Thienpont et al. 1974 ) or thiabendazole (Campbell and Cuckler 1964), kills the larval parasite and results in death of the nurse cell.

The mature larvae are not inactive but probe their intracellular environment. As discussed in Despommier (1990), the L1 are reported to rock back and forth in a rhythmic fashion within the nurse cell sarcoplasm. Additionally, the anterior end of L1 was observed to probe its microenvironment, the nurse cell sarcoplasm, with short in-and-out movements.

\section{Nurse Cell Capsule Formation}

Histological evidence shows that the nurse cell capsule (Bruce 1970, Teppema et al. 1973 ) and formation of the circulatory rete (Humes and Acker 1952) can be detected on day 12-13 post-infection . As discussed in Baruch and Despommier (1991), day 12 postinfection corresponds to day 6 of the actual muscle infection. The largest deposition of capsule material occurs from about day 20 post- infection and is largely complete by day 30 post-infection. This time frame is equivalent to day 10 to day 20 post muscle penetration. 
Apart from eventual calcification, there are no significant changes in the nurse cell-parasite complex and the host-parasite relationship can remain stable for years (Despommier 1990).

While the actual formation of the capsule is not clear, it is suggested that it is of host origin and/or response. Jasmer (1990) suggests that constant perturbations and/or the response of inflammatory cells (Jasmer 1993) may result in the characteristics of the nurse cell, including formation of the collagen capsule. Teppema et al. (1973) concludes that the capsule is deposited between the sarcolemma and the basal lamina and formed from or by the infected muscle fiber. He further suggests that comparisons between the morphological characteristics of the capsule substance and the sarcolemmal basal lamina are justified.

Bruce (1970) attributes capsule formation to both the infected muscle fiber and the surrounding host tissue, with the basic framework being the sarcolemma and basement lamella of the parasitized muscle fiber. Bruce (1970) also reports that even as far back as the nineteenth century, the sarcolemma was thought to be involved.

\section{$\underline{\text { Nurse Cell Structure }}$}

The nurse cell's structure and composition was previously examined using microscopy and electron microscopy. In summary, it consists of altered host sarcoplasm in which the infective $\mathrm{L} 1$ reside. The altered host sarcoplasm is enclosed by a compacted fibrous capsule, ultimately surrounded by a circulatory rete (Despommier 1990). See Figure 3. Within the nurse cell population, Despommier et al. (1991) reports great variability in the amount of collagen deposited along the nurse cell's outer surface and also in the complexity of the circulatory rete.

The nurse cell's altered sarcoplasm is thought to be an area of high metabolic activity based on positive reactions to histochemical tests for enzymes and the proliference of organelles such as mitochondria, rough and smooth endoplasmic reticulum, and Golgi complexes (Bruce 1970). The altered sarcoplasm can be classified as a syncytium because 


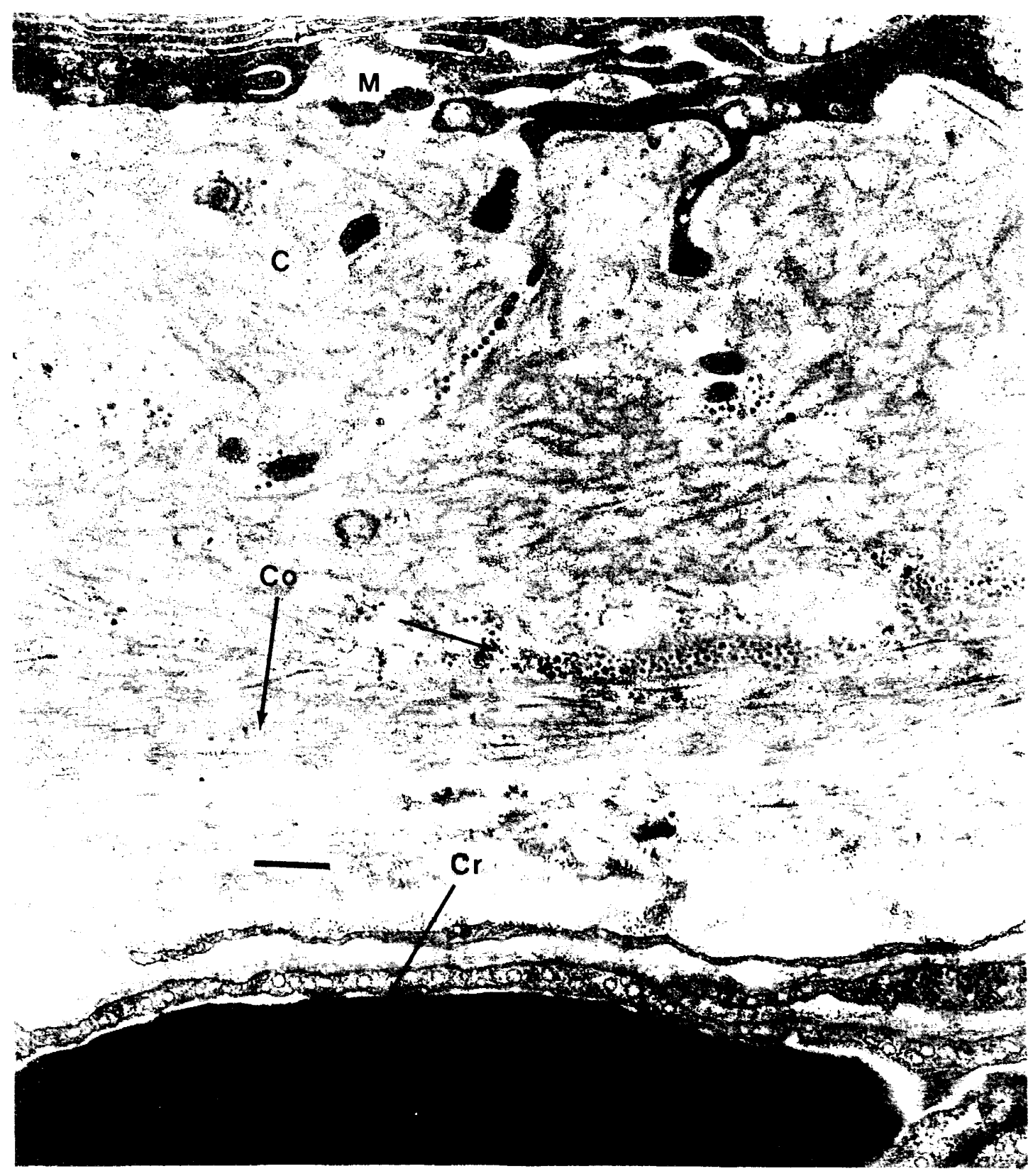

Figure 3. Electron micrograph of the nurse cell capsule. Note the fibrous character of the capsule (C). Compacted fibrils (Co) lie in the outer region and are mixed with amorphous material within the inner region. A vessel of the circulatory rete $(\mathrm{Cr})$ is seen outside the capsule. Whorls of smooth membranes are seen within the matrix $(\mathrm{M})$ of altered host sarcoplasm. Magnification, 28,000×, bar $=360 \mathrm{~nm}$. 
there is no evidence of cell "walls" separating the many nuclei (Bruce 1970).

The nurse cell capsule is often described as compacted, fibrous and consisting of collagen (Bruce 1970, Teppema et al. 1973, Despommier 1975). The capsule's maximum thickness is between 10 and $30 \mu \mathrm{m}$ (Teppema et al. 1973). The capsule can be divided into outer and inner regions based on histological staining for collagen fibrils (Bruce 1970). The outer portion of the capsule is more heavily stained for collagen using the Van Giehoff stain and shows more fibrils with electron microscopy.

Tests for collagen, cystine, and carbohydrate strongly react with the outer region of the capsule as compared to the inner region which has a more moderate reaction (Bruce 1970). Periodic Acid Schiff, which stained the capsule strongly (Bruce 1970), enables the localization of carbohydrate-rich macromolecules including glycogen, proteoglycans, and glycoproteins within tissue (Padykula 1988). Reticulin, an early term for collagen type III (Goldberg and Rabinovitch 1988), is located on the extreme outer portion of the capsule wall (Bruce 1970). Tests for glycogen react with both the outer and inner regions of the capsule. Unlike the nurse cell's altered sarcoplasm, the capsule tests virtually free of enzymes, except for a non-specific esterase (Bruce 1970).

Both Bruce (1970) and Teppema et al. (1973) conclude that the outer capsule wall is composed of tightly packed fibrils while the inner region has fibrils loosely arranged among vesicles and amorphous substances. However, Teppema et al. (1973) argued that a periodicity reminiscent of collagen is locally present in the fibers. This disagrees with the findings of Bruce (1970) who maintains that the fibrils do not exhibit the classical axial banding pattern of true collagen. Both Ritterson (1966) and Bruce (1970) determined that the nurse cell capsule is digested readily with collagenase. 
EXTRACELLULAR MATRIX PROTEINS

\section{Collagen}

The class of molecules that comprise the collagen family of proteins dominates the composition of the extracellular matrix. Several genetically and structurally distinct collagens exist. At least 14 are known to exist with more being distinguished through current research efforts (van der Rest and Garrone 1991). Because all collagens contain significant but variable amounts of covalently linked carbohydrate, they are also considered to be glycoproteins (Miller 1984).

All collagens share a basic molecular structure that contains one or more domains having a characteristic triple helix made of Gly-Xaa-Yaa repeats, where Xaa is most often proline and Yaa is most often hydroxyproline (Morris et al. 1990). Collagens are classified into three subclasses (van der Rest and Garrone 1991): the fibril-forming collagens, the nonfibrillar or sheet collagens, and the fibril-associated collagens with interrupted triple helices (FACITs). Type II and type IX collagen are cartilage specific and type X collagen is specific to the growth plate of bone (Mendler et al. 1989) and, therefore, are not likely to be components of the nurse cell capsule.

Fibrillar Collagens. The fibrillar collagens, types I, II, III, V, and XI, form the striated quarter-staggered fiber system characteristic of the extracellular matrix (van der Rest and Garrone 1991). The fibrillar class of collagens are composed of chains with molecular weights greater than $95 \mathrm{kD}$ (Miller and Gay 1987). The fibrillar collagens are also genetically related through derivation from a single ancestral gene (Vuorio and De Crombrugghe 1990).

In addition to sharing a common function of providing structural support, the fibrillar collagens have related structural features. Morris et al. (1990) summarize the main characteristics of the fibrillar class of collagens: a single uninterrupted triple helical domain $300 \mathrm{~nm}$ in length, a high degree of amino acid sequence homology, conservation of gene 
structure, and similar proteolytic processing of their procollagens.

Types I and III collagen are ubiquitous components of connective tissue and play a role in the healing of wounds (Hurme et al. 1991). Type III collagen is a significant component of distensible connective tissue (Miller 1984). Levels of type III collagen increase as the level of distensibility in the structure increases.

There is increasing evidence, as discussed in Mayne et al. (1993), that suggests type V collagen and type XI collagen are not separate collagen types, but are actually part of a collagen family in which chains from both type $\mathrm{V}$ and type $\mathrm{XI}$ form native molecules. The $\alpha 1(\mathrm{XI})$ chain and the $\alpha 2(\mathrm{~V})$ chain can form a single molecule and may serve as a core fibril for the assembly of type I and type III collagens. It is postulated that both type V collagen (Adachi and Hayashi 1986) and type XI collagen (Mendler et al. 1989) limit the lateral growth of collagen fibrils.

Type V collagen is present in most connective tissues (Mayne et al. 1993). Type V collagen is associated closely with cells and may have an exocytoskeleton function (Miller 1984). Type $V$ collagen is found in close contact with basal membranes, but is not considered a component of these (Romanos et al. 1991). Type $\mathrm{V}$ collagen is also an important component in the formation of granulation tissue and wound healing (Hering et al. 1983, Narayanan et al. 1983). Type XI collagen has previously been considered cartilage specific (Mendler et al. 1989), but recent evidence suggests that type XI chains can be found in many non-cartilagenous tissues (Mayne et al. 1993).

Nonfibrillar Collagens. The nonfibrillar collagens, or sheet and membrane forming collagens, include types IV, VI, VII, VIII, and X (van der Rest and Garrone 1991). Like the fibrillar class, the nonfibrillar collagens are composed of chains with molecular weights greater than $95 \mathrm{kD}$ (Miller and Gay 1987).

Type IV and type VI collagens share further structural features, as discussed in Miller and Gay (1987). The alpha chains of type IV and type VI collagens have many 
interruptions of the major collagenous domain. Also, both type IV collagen and type VI collagen molecules are assembled in an antiparallel orientation to form tetrameric aggregates which in turn assemble into larger aggregates in an end-to-end fashion.

Type IV collagen has, in its most common form, two $\alpha 1$ (IV) chains and one $\alpha 2$ (IV) which form a heterotrimeric molecule (van der Rest and Garrone 1991). Type IV collagen is a highly conserved molecule in evolution (Timpl 1989, van der Rest and Garrone 1991). It is a main component of basement membranes and is able to covalently interact with other basement membrane proteins (Timpl 1989). Type IV collagen forms a polygonal network which acts as a scaffold and is suitable for the selective filtration of large molecules (Yurchenco and Schittny 1990). The frequent interruptions of its triple helix confer flexibility to the molecule and elasticity to the network. In all, there are 25 interruptions of the triple helical region (Timpl 1989).

Type VI collagen is classified as a nonfibrillar collagen made of three polypeptide chains, $\alpha 1$ (VI), $\alpha 2$ (VI) and $\alpha 3$ (VI) which are assembled into a heterotrimeric molecule (van der Rest and Garrone 1991). Type VI collagen is a large, disulfide bonded molecule with a short triple helical domain containing two imperfections and large nontriple helical amino and carboxyl regions. Its three polypeptide chains contain 11 clusters of characteristic arginine-glycine-aspartate (RGD) sequences.

As discussed in Engel et al. (1985), type VI collagen molecules form aggregates which are stabilized by disulfide bonds: two molecules assemble head-to-tail forming a dimer; dimers assemble into tetramers, and tetramers associate linearly. This aggregate structure forms characteristic beaded filaments as demonstrated by rotary shadowing.

The occurrence of type VI collagen in connective tissue is widespread and has been demonstrated by immunohistological surveys in tissues such as large vessels, skin, liver, kidney and muscle (Von der Mark et al. 1984). Immunohistochemical surveys have found that type VI collagen is not typically found in basement membranes (Von der Mark et al. 
1984) but it is in the vicinity (Rabanus et al. 1991).

Type VI collagen is common in wound healing (Oono et al. 1993), and in the pathology of fibrotic disease (Katsuda et al. 1992) and tumors (Chanoki et al. 1991, Becker et al. 1991). Type VI collagen is thought to be a microfibrillar extracellular matrix component, forming a network in diverse structures of the body such as most connective tissue, the aortic intima (Von der Mark et al. 1984), synovial interstitium (Ashhurst et al. 1991), and dental pulp (Shuttleworth et al. 1992).

While the exact function of type VI collagen is not known, several theories have emerged (van der Rest and Garrone 1991). Type VI collagen networks have been found together with the fibrillar collagens suggesting a function in the interface between cells and the main collagen fibril network (van der Rest and Garrone 1991). Additionally, type VI collagen may function in cell attachment and spreading of several types of cells including fibroblasts (Doane et al. 1992).

\section{Glycoproteins}

Laminin. Lamipin (Timpl et al. 1982) and tenascin (Chuong and Chen 1991) are glycoproteins of the extracellular matrix which function as adhesive proteins. Laminin is a flexible four-armed glycoprotein and a normal, ubiquitous component of basement membranes (Timpl et al. 1982). Laminin forms a polymer network by itself and in association with type IV collagen (Yurchenco and Schittny 1990).

Laminin has adhesive functions which include a prominent role in the formation of extracellular matrices during embryonic morphogenesis, cell aggregation, and the attachment of cells to substrates (Timpl et al. 1982).

Tenascin. Tenascin is prominently expressed during embryonic development, wound healing, and tumor growth (Natali and Zardi 1989). Tenascin expression is normally very reduced in adults (Chuong and Chen 1991). Only some adult tissues, such as tendons, 
have low tissue concentrations of tenascin. Tenascin expression is enhanced by betatransforming growth factor ( $\beta$ TGF) which is known for its role in the enhancement of wound healing (Sporn et al. 1987).

Chuong and Chen (1991) found that antibody directed against tenascin localized at the point of tissue injury and within activated connective tissue between newly formed collagen fibrils. They also report that tenascin completely disappears from the wound and scar tissue when healing is complete. Then expression of tenascin returns to normal low levels.

\section{Normal Muscle}

Extracellular matrix proteins and several of the collagen types are known to be associated with normal connective tissue of muscle. Immunofluorescence studies have established the presence of fibrillar collagen types I, III, and V in muscle (Bailey et. al. 1979). Type I collagen is associated primarily in the epimysium and perimysium, type III collagen in the perimysium, and type V collagen in the endomysium. Type VI collagen is known to be a prominent component of the interstitial connective tissue of muscle (Von der Mark et al. 1984).

Basement membranes lie in close proximity to epithelial, endothelial, muscle, and nerve cells (Timpl 1989). Skeletal muscle is surrounded by a basement membrane (Yurchenco and Schittny 1990). Experiments have shown that the basement membrane proteins, type IV collagen and laminin, occur in the membranes surrounding all skeletal muscle cells (Reddi 1984). Cardiac and smooth muscle also have a basement membrane (Martinez-Hernandez and Amenta 1983).

\section{THE BASIS FOR PEPSIN DIGESTION}

One of the most widely used analytical procedures for the identification of collagen types is polyacrylimide gel electrophoresis in sodium dodecyl sulfate (SDS-page) following 
pepsin digestion (Miller and Rhodes 1982). SDS-page is sensitive, provides high resolution, and only requires microgram quantities of sample protein. Other methods of chromatography require milligram amounts of sample protein (Miller 1984). Typical sources of extracellular matrix proteins, such as collagen, include tumors, placentas, cell cultures, and bones which provide high yields of sample material. Large quantities of sample material are not available from nurse cell capsules in this experimental situation.

Pepsin is a strong, acidic, general protease and is the principal proteolytic enzyme of gastric secretions (Worthington 1988, Laas 1989). Pepsin has a pH optimum of 1.6-3.2 (Ganong 1989). Pepsin cleaves proteins preferentially at the carboxylic groups of aromatic amino acids such as phenylalanine, leucine, tryptophan, and tyrosine (Worthington 1988). It does not cleave bonds containing glycine, alanine, or valine.

Collagen molecules contain several pepsin labile domains, including nonhelical extension peptides (also referred to as telopeptides) at the amino and carboxyl terminal ends of each component alpha chain (Piez 1976). These regions are globular in conformation and contain the covalent cross-links responsible for collagen insolubility. The globular domains, lacking the Gly-Xaa-Yaa repeat, are susceptible to pepsin digestion whereas the triple-helical portion of the molecule is not (van der Rest and Garrone 1991).

Treatment of a tissue sample with acidified pepsin accomplishes several things which aid collagen research. Pepsin digestion solublizes collagen and it partially purifies the sample by degrading many types of noncollagenous proteins. Pepsin digestion produces intact characteristic pepsin resistant fragments that constitute the triple-helical portion of collagen molecules (Miller 1972, Linsenmayer 1981). Pepsin digestion also yields a proteolytic resistant laminin fragment designated P1 (Timpl et al. 1982, Timpl 1989). The pepsin resistant fragments can then be analyzed by SDS-page under both reducing and nonreducing conditions. This is the basis for limited pepsin digestion (Miller 1972). 
Electrophoretic Properties

As discussed in Miller (1984), types III, IV, and VI collagens are disulfide bonded molecules. Reduction with beta-mercaptoethanol, prior to SDS-page, permits the separation of triple helical fragments on polyacryilamide gels which would otherwise migrate as trimers of disulfide linked alpha chains. Variability in the range of reported molecular weights for pepsin resistant fragments is due to differences in experimental conditions and limits the ability to identify a fragment solely by its molecular weight.

Engel et al. (1985) provides a summary of the structure and character of type VI collagen. Intact monomers of type VI collagen have an estimated molecular weight of 400$600 \mathrm{kD}$ (Colombatti et al. 1992). Type VI collagen has three unique alpha chains, $\alpha 1$ (VI), $\alpha 2(V I)$, and $\alpha 3(V I)$. Each alpha chain of type VI collagen has a molecular weight of 140 $\mathrm{kD}$ and the smallest proportion of the triple-helical domain of the known collagens (Miller and Gay 1987). However, both Colombatti et al. (1992) and Oono et al. (1993) report that both the $\alpha 1(\mathrm{VI})$ and the $\alpha 2(\mathrm{VI})$ chains have a molecular weight of $140 \mathrm{kD}$, while the $\alpha 3(\mathrm{VI})$ chain has a molecular weight in the range of $250-300 \mathrm{kD}$.

Engel et al. (1985) report that pepsin digestion of a type VI collagen monomer results in the loss of eighty percent of its globular domains' mass. Furthermore, the constituent polypeptide alpha chains of type VI collagen are degraded to fragments of about half their normal size after pepsin digestion. Additionally, they report that solubilization of type VI collagen, by pepsin treatment, leaves a highly associated complex with a molecular weight of $350 \mathrm{kD}$ which slowly enters polyacrylamide gels.

The alpha chains of type VI collagen are highly disulfide linked (Engel et al. 1985). In tissues, type VI collagen molecules are also structurally crosslinked. Denaturation and reduction of the disulfide bonds of type VI collagen yields two or three constituent chains with molecular masses in the range of $40 \mathrm{kD}$ to $70 \mathrm{kD}$ (Miller and Gay 1987, Engel et al. 1985). 
Engel et al. (1985) also report that treatment of type VI collagen with pepsin produced a triple stranded structure with bands of molecular weight of $50 \mathrm{kD}, 70 \mathrm{kD}$, and a monomer of $170 \mathrm{kD}$ which could ultimately be degraded to a $35 \mathrm{kD}$ fragment. Colombatti et al. (1992) report the production of pepsin resistant fragments from the $\alpha 1$ (VI), $\alpha 2$ (VI), and $\alpha 3$ (VI) chains with molecular weights of $66 \mathrm{kD}, 50 \mathrm{kD}$, and $45 \mathrm{kD}$ respectively.

Type IV collagen consists of two $\alpha$ (IV) chains and one $\alpha 2$ (IV) chain with molecular weights of $185 \mathrm{kD}$ and $170 \mathrm{kD}$ respectively (Miller and Gay 1987). As reported in Kuhn et al. (1985), pepsin digestion of tetrameric type IV collagen cleaves the molecule mainly in 2 positions. The first cleavage results in the production of a $330 \mathrm{~nm}$ long fragment, the $\alpha 1$ (IV) 140 with a molecular weight of $140 \mathrm{kD}$. The second cleavage produces a $265 \mathrm{~nm}$ fragment, which, when subsequently treated with pepsin and denatured, yields two fragments: $\alpha 1$ (IV) 95 and $\alpha 2$ (IV) 70 with molecular weights of $95 \mathrm{kD}$ and $70 \mathrm{kD}$ respectively.

The alpha chains of the fibrillar collagens have known electrophoretic migration patterns (Miller 1984). The $\alpha 1$ (II) and $\alpha 1$ (III) chains migrate identically to the $\alpha 1$ (I). Although the $\alpha 2$ (I) chain has the same molecular weight, $95 \mathrm{kD}$, as the $\alpha 1$ (I) chain, it migrates with slightly greater mobility. The disulfide-bonded type III collagen is readily reduced to separate its constituent $\alpha$ (III) chains which comigrate with $\alpha 1$ (I) chains.

Type XI collagen is a heterotrimer with the chain composition $\alpha 1 \alpha 2 \alpha 3$ (Morris and Bachinger 1987). The electrophoretic migration patterns of the alpha chains of type I collagen (Morris and Bachinger 1987), type II (Eyre et al. 1984), and types I and V (Furuto et al. 1991) have been shown in relation to the $\alpha 1 \alpha 2 \alpha 3$ chains of type XI. The $\alpha 3$ chain of type XI appears identical to the $\alpha 1$ (II) chain. Type V collagen appears in alternative forms $\alpha 1(\mathrm{~V}), \alpha 1(\mathrm{~V}), \alpha 2(\mathrm{~V})$ or $\alpha 1 \alpha 2 \alpha 3$ depending on the tissue source (Morris et al. 1990). Although the $\alpha 1(\mathrm{~V})$ and $\alpha 2(\mathrm{~V})$ chains of type $\mathrm{V}$ collagen and the other fibrillar collagens are approximately the same size after pepsin digestion, type $\mathrm{V}$ chains migrate as 
apparently larger molecular weight polypeptides (Miller 1984). The $\alpha 1(\mathrm{~V})$ and $\alpha 2(\mathrm{~V})$ chains are similar to the $\alpha 1$ and $\alpha 2$ chains of type XI collagen (Thom and Morris 1991, Morris and Bachinger 1987, Mendler et al. 1989). Therefore, the $\alpha 1 \alpha 2 \alpha 3$ chains of type $\mathrm{XI}$ collagen are used as markers for alpha chains characteristic of the fibrillar class of collagens.

Laminin is a large glycoprotein with a molecular weight of approximately $900 \mathrm{kD}$ (de Sousa et al. 1991). Laminin also has structural domains that are resistant to proteolytic digestion (Timpl et al. 1982, Hakomori et al. 1984, Timpl 1989). Digestion of laminin with pepsin produces a major fragment, called $\mathrm{P} 1$, with a molecular weight of $260 \mathrm{kD}$ to $350 \mathrm{kD}$ (Rao et al. 1982). Timpl et al. (1982) report the molecular weight of the P1 fragment to be $290 \mathrm{kD}$. Reduction of the $\mathrm{P} 1$ fragment yields two fragments with molecular weights of $160-180 \mathrm{kD}$ and $130-140 \mathrm{kD}$, respectively (Rao et al. 1982).

Timpl (1982) also reports the production of a $\mathrm{P} 2$ fragment, molecular weight $45 \mathrm{kD}$, from laminin after digestion with pepsin. Otto et al. (1982) also reports the production of a second peptide fragment of molecular weight $50 \mathrm{kD}$ (reduced), after digestion with pepsin.

\section{Isolation And Analysis Of Intact Nurse Ceils}

Jasmer (1990) demonstrated that intact nurse cells can be isolated from infected host muscle by sequential protease treatments. This method of tissue dissociation employs pronase, collagenase, and hyaluronidase. These enzymes break down the surrounding host muscle tissue and extracellular matrix but release intact nurse cells with minimal damage. The nurse cells can then be analyzed by methods such as SDS-PAGE.

Pronase is a nonspecific protease, isolated from Streptomyces griseus, which is commonly used in tissue dissociation applications. Collagenase preparations have a combination of collagenolytic and proteolytic activities essential for tissue dissociation. Collagenase degrades the helical regions of native collagen preferentially at the Yaa-Glycine 
bond in the sequence Pro-Y-Gly-Pro- where $\mathrm{Y}$ is most frequently a neutral amino acid (Worthington 1988). Hyaluronidase hydrolyzes the glycosidic linkages of hyaluronic acid and chondroitin sulfate (Lehninger 1982).

Pepsin digestion of isolated intact nurse cells is expected to be a reliable method of obtaining a sample of uncontaminated collagen from the nurse cell capsule. First, the nurse cell's altered sarcoplasm does not contain collagen which could potentially contaminate the sample under analysis (Bruce 1970). Secondly, after digestion, the soluble sample can be separated from the intact larvae through centrifugation (Jasmer 1990). Also, it is known that the accessory layer of the cuticle remains on during pepsin-HCL digestion of first stage larvae in vitro (Wright and Hong 1989). Furthermore, the accessory layer of the cuticle is not digested or removed by the action of intestinal factors, in vivo, but remains on the larvae until the cuticle is lost during the first molt (Capo et al. 1984). Therefore, neither the encysted larvae nor the altered sarcoplasm of the nurse cell is a likely source of contaminating protein. 


\section{MATERIALS AND METHODS}

\section{ESTABLISHMENT OF INFECTION}

\section{$\underline{\text { Animals }}$}

Rats and mice were used as experimental hosts. Nine 3 month old rats were infected orally with ground meat containing $800 \mathrm{~L} 1$. Seven MRL++ mice were infected with 200 L1. The animals were restricted from food and water for four hours and then fed a dose of infected meat that was moistened with ringer's solution. The number of infective larvae contained in one gram of ground meat was estimated by counting the free larvae of the digestion of a weighed aliquot of meat. The meat was digested in a $2.0 \%$ pepsin (Sigma) solution that was acidified to $\mathrm{pH} 1.8$ with drops of $\mathrm{HCl}$ and incubated at $37^{\circ} \mathrm{C}$, for approximately 10 minutes, or until the meat was digested and the larvae liberated. The free larvae were then counted. (Animals were supplied by Portland State University).

\section{ANALYSIS OF NURSE CELLS}

\section{Isolation Of Nurse Cells}

Nurse cells were isolated from host muscle tissue according to the methods of Jasmer (1990). MRL++ mice and laboratory rats that had carried infections from 3 months to 1 year served as experimental hosts. Mice were killed by cervical dislocation and rats were killed by a single blow to the head. The carcasses were skinned, eviscerated, and decapitated (rats were also deboned). The carcasses were finely ground in a common household meat grinder. The ground tissue was then rinsed 3 times in Hank's Balanced Salt Solution Glucose (HBSSG), pH 7.4. The infected tissue was digested in $0.25 \%$ pronase (Boehringer Mannheim, No. 165921) in HBSSG (45 ml per mouse carcass) and 
( $1.0 \mathrm{ml}$ per gram of rat tissue) for 40 minutes at $37^{\circ} \mathrm{C}, \mathrm{pH} 7.4$. The sample was briefly centrifuged to pellet floating tissue and then rinsed 3 times in HBSSG. (Pronase was kindly supplied by Portland State University).

The pellet was resuspended in HBSSG (20 ml per mouse carcass) and $(0.9 \mathrm{ml}$ per gram of rat tissue), at pH 7.4, to just cover the tissue. The pellet was further digested in a mixture of collagenase (Sigma, C-2399 and Worthington, C-152) and hyaluronidase (Sigma, $\mathrm{H}-3884$ ) $1 \mathrm{mg} / \mathrm{ml}$ of each, at $37^{\circ} \mathrm{C}$. The digestion was allowed to proceed for 40 minutes, or until the nurse cells were released from host muscle tissue, with occasional vigorous stirring. The digestion was inspected every 15 minutes to determine the release of nurse cells.

The latter digestion released intact nurse cells. The nurse cells were separated from host cellular debris by passing the slurry through a series of screens. Undigested tissue and bones were separated from the nurse cells by passing the slurry through a coarse (2-mm pore) screen followed by a fine (1-mm pore) screen. The flow-through, which contained intact nurse cells, was then passed over fine screens ( 72 microns) which retained the nurse cells and removed supernatant. Sample material, that was not in the process of being rinsed and screened, was kept at $4^{\circ} \mathrm{C}$.

The intact nurse cells were washed with HBSSG containing $1 \mathrm{mM}$ EDTA, final $\mathrm{pH}$ 7.4 , until clean of remaining host debris. The sample was further cleaned by hand pipetting any host debris away from the nurse cells. The nurse cells were centrifuged, at half speed for 5 minutes, allowed to settle into a pellet, and the supernatant drawn off. The intact nurse cells were then frozen at $-20^{\circ} \mathrm{C}$ until ready for the pepsin digestion. The enzymes, collagenase (Worthington, C-152) and hyaluronidase (Sigma, H-3884), were a kind gift from the Research Unit, Shriner's Hospital. The enzyme collagenase (Sigma, C-2399) was supplied by Portland State University. 
Pepsin Digestion Of Nurse Cells

Protease digestion of collagen samples with pepsin was performed, with modifications, according to the methods of Bruckner and Prockop (1981). Protease digestion was initiated by first suspending the sample pellet in $0.3 \mathrm{M} \mathrm{HCl}$ to acidify (to a $100 \mu 1$ sample pellet of nurse cells, add $500 \mu 1$ of $0.30 \mathrm{M} \mathrm{HCl}$ to total $600 \mu 1)$. Next, an acid protease, pepsin (Sigma), was added at a 1:10 ratio of enzyme solution to total sample volume. To the acidified nurse cell sample, one tenth volume $(60 \mu 1)$ of pepsin solution (1.5 $\mathrm{mg} / \mathrm{ml}$ pepsin in $10 \mathrm{mM}$ acetic acid) was added. The nurse cell-pepsin sample preparation was $\mathrm{pH} 3.0$. The stock $1.5 \mathrm{mg} / \mathrm{ml}$ pepsin in $10 \mathrm{mM}$ acetic acid solution was prepared by adding $122 \mu 1$ of $10 \mathrm{mM}$ acetic acid to $10 \mu 1$ of $20 \mathrm{mg} / \mathrm{ml}$ pepsin. Pepsin digestion was carried out at room temperature for a period of 2.5 and 4.5 hours, with continuous mixing on a nutator mixer.

The pepsin digestion was terminated by adding unbuffered $1.0 \mathrm{M}$ Tris. The ratio of Tris to sample preparation was 1:5. The final $\mathrm{pH}$ was 7.0. The nurse cell-pepsin digestion sample preparation was then centrifuged briefly to pellet the intact larvae. The supernatant, which contained the soluble collagen sample, was removed for analysis by SDS-page.

The nurse cell-pepsin digestion samples were then prepared for SDS-page electrophoresis. The sample buffer was prepared by making a solution containing $0.5 \mathrm{ml}$ of $20 \% \mathrm{SDS}, 0.5 \mathrm{ml}$ of glycerol, $100 \mu 1$ of saturated solution of bromphenol blue, and betamercaptoethanol $40 \mu 1$ if reduction was desired. Sample buffer was added to the nurse cellpepsin digestion sample preparation as follows: to $80 \mu 1$ of the nurse cell-pepsin digestion sample add $20 \mu 1$ fresh sample buffer.

The samples were heated to $95^{\circ} \mathrm{C}$ for 3 minutes and then subjected to SDS-page electrophoresis. The lane wells were filled to capacity with sample material and the authentic collagen markers. The nurse cell-pepsin digestion sample was run with authentic collagen markers as standards of the apparent molecular weight of collagen fragments: type 
VI collagen and the $\alpha 1 \alpha 2 \alpha 3$ chains of type XI collagen, a pepsin marker (molecular weight $35 \mathrm{kD}$ ), and Bio-Rad prestained standard high and low molecular weight markers (all a kind gift from the Research Unit, Shriner's Hospital).

\section{SDS-page Electrophoresis}

Electrophoresis was carried out according to the methods of Laemmli (1970) and as described in Sambrook et al. (1989). Determination of the pepsin resistant fragments' molecular weight was done according to the method described in Laas (1989). The gels were cast according to the manufacturer's instructions for the use of ProtoGel, a 37.5:1 acrylamide to bisacrylamide stabilized solution (National Diagnostics, Atlanta, No. EC892). The stacking gel buffer was prepared as follows: (30.3 grams Tris, $5.0 \mathrm{ml}$ TEMED, $500 \mathrm{ml}$ deionized water, brought to $\mathrm{pH} 6.8$ with $\mathrm{HCl}$ ). The running gel buffer was prepared as follows: (181.7 grams Tris, $10.0 \mathrm{ml}$ TEMED, $1000 \mathrm{ml}$ deionized water, and brought to $\mathrm{pH} 8.8$ with $\mathrm{HCl}$ ). A $4 \mathrm{X}$ stock tank buffer was prepared by making the following solution: (57.4 grams glycine, 70.0 grams Tris, 4.0 grams SDS, $1000 \mathrm{ml}$ deionized water, and brought to $\mathrm{pH} 8.3$ with $\mathrm{HCl}$ ).

A large running gel of $8.5 \%$ polyacrylamide (Protogel, National Diagnostics) and a $3 \%$ stacking gel, were left to run overnight at 40 volts constant voltage. Minigels were run with $3 \%$ stacking gels and running gels of $8.5 \%, 7.5 \%$ and $5 \%$ at 100 volts constant voltage until the tracking dye reached the bottom of the gel (approximately $1 \mathrm{hr} .15 \mathrm{~min}$.). The gels were fixed for 15 minutes in the following solution (50\% methanol, $7 \%$ acetic acid in deionized water to make 100\%), stained with Comassie Brilliant Blue dye for 15 minutes, and then destained overnight in the following solution (10\% methanol, $7 \%$ acetic acid, in deionized water to make $100 \%$ ). Photographs were taken for a permanent record. (Materials were a kind gift of the Research Unit, Shriner's Hospital). 


\section{Electron Microscopy}

A diaphragm from a MRL++ mouse carrying a 3 month old infection of $T$. spiralis was fixed in 1.5\%:1.5\% glutaraldehyde:paraformaldehyde for 60 minutes at $4{ }^{\circ} \mathrm{C}$ and then rinsed in $0.1 \mathrm{M} \mathrm{Na}$-cacodylate for 45 minutes at $4^{\circ} \mathrm{C}$. The sample tissue was left overnight in $0.1 \mathrm{M} \mathrm{Na}$-cacodylate at $4^{\circ} \mathrm{C}$. The following morning, the sample was incubated for 60 minutes in $1 \%$ OsO4. The sample was subsequently rinsed 3 times over 15 minutes in 0.1 $\mathrm{M} \mathrm{Na}$-cacodylate at $4^{\circ} \mathrm{C}$. The sample was then dehydrated for 15 minutes each in a series of EtOH from $30 \%$ to $90 \%$ at room temperature. Following serial dehydration, the sample was rinsed 3 times over 45 minutes in $100 \% \mathrm{EtOH}$ at room temperature. The tissue sample was then rinsed 3 times over 45 minutes in 100\% propylene oxide.

The tissue sample was then transferred to a series of rinses in propylene oxide:Spurr's epoxy for 60 minutes each in a ratio of 1:1,1:2,1:3 at room temperature. The sample was then rinsed for 3 hours in 100\% Spurr's epoxy and then embedded in 100\% Spurr's epoxy, all at room temperature. The sample was polymerized in $100 \%$ Spurrs epoxy at $70^{\circ} \mathrm{C}$. The tissue section was subsequently stained for 15 minutes in uranyl acetate and 4 minutes in lead citrate formvar. (Electron microscopy services, including tissue fixation and embedding, the production of grids, and electron micrographs were a kind gift of Doug Keene and Cathy Ridgeway, Electron Microscopy Department, the Research Unit, Shriner's Hospital. Additionally, electron micrographs were kindly produced by Ken Tiekotter, Good Samaritan Hospital).

\section{Frozen Tissue Embedding}

Tissues were preserved using either of the following two methods for freezing fresh tissue. Diaphragms were removed from both noninfected rats and rats carrying a one year old infection, cut into small pieces and embedded in OCT mounting media ("Tissue Tek", 
Miles Scientific, Inc.) containing $3.0 \mathrm{ml}$ of glycerine per a 4 fluid ounce bottle of OCT. The OCT block, which contained the sample tissue, was frozen in a slurry of isopentane (2-methyl butane) that was pre-chilled in liquid nitrogen (Morrison et al. 1990, McNeil and Khakee 1992). The block was stored at $-80^{\circ} \mathrm{C}$ until ready to section.

Alternatively, the diaphragms were removed, cut into small pieces and preserved by freezing the tissue in hexane pre-cooled on dry ice. The tissues were then stored in hexane at $-80^{\circ} \mathrm{C}$ until ready to section. Diaphragms were removed from the hexane and embedded in OCT compound. Slides were prepared by cutting 5 micron thick frozen tissue sections on a cryostat at $-20^{\circ} \mathrm{C}$ and transferring to a poly-l-lysine (Sigma, No. P-8920) coated slide. The slides were fixed in cold $\left(4^{\circ} \mathrm{C}\right)$ methanol for 15 minutes, air dried, and either immediately processed through the indirect immunofluorescence antibody protocol or stored at $-20^{\circ} \mathrm{C}$ until ready for use. (OCT compound was kindly provided by the Research Unit, Shriner's Hospital. Poly-1-lysine was kindly provided by Portland State University and the Research Unit, Shriner's Hospital).

\section{$\underline{\text { Indirect Immunofluorescence }}$}

Indirect immunofluorescent staining procedures are described in Romanos et al. (1991) and Timpl (1984) and were performed according to the protocol followed by the Research Unit, Shriner's Hospital. Antibodies were reconstituted according to their manufacturer's instructions and stored at $-20^{\circ} \mathrm{C}$. The antibodies were diluted according to the manufacturer's suggestions for the application of indirect immunofluorescence. Each slide received an application of $200 \mu 1$ of primary antibody solution.

Slides were rehydrated in a $1 \mathrm{X}$ phosphate buffered saline (PBS) bath 2 times for 5 minutes each. The following primary polyclonal rabbit antibodies were applied $(200 \mu 1$ per slide): Shriner's Hospital Serum No. 4876 anti-type XI collagen (which also recognizes type $V$ collagen) at dilutions of 1:25, and 1:50; Shriner's Hospital affinity purified anti-type 
VI collagen, Serum No. 4104 Bound-fraction at dilutions of 1:100, and 1:250; Shriner's Hospital anti-type VI collagen, Serum No. 4104 Unbound-fraction at dilutions of 1:250, 1:500, and 1:750 (the antibodies listed above were the kind gift of the Research Unit, Shriner's Hospital); anti-type VI collagen (Gibco BRL, catalog No. A112) at dilutions of 1:100, 1:250, 1:500, and 1:750; anti-rat laminin (Gibco BRL, catalog no. A106) at dilutions of 1:100, 1:250, 1:500, 1:750, and 1:1000 (Gibco BRL antibodies were the kind gift of Anonymous, Gibco BRL); anti-type IV collagen (Biodesign International, catalog No. T40263R) at dilutions of 1:100, 1:500, and 1:1000; and anti-human tenascin (Telios Pharmaceuticals, Inc., catalog No. A107) at dilutions of 1:100, 1:500, and 1:1000 (antibodies against type IV collagen and tenascin were the kind gift of the Casey Eye Institute).

The following affinity purified polyclonal goat antibodies (Southern Biotechnology Associates, Inc.) were applied ( $200 \mu 1$ per slide): anti-type VI collagen (catalog No. 136001) at dilutions of 1:50, 1:100, and 1:250; anti-type I collagen (catalog No. 1310-01) at dilutions of 1:50, 1:100, 1:250, 1:500, and 1:1000, and anti-type III collagen (catalog No. 1330-01) at dilutions of 1:50,1:100,1:250, 1:500, and 1:750. (Southern Biotechnology Associates, Inc. kindly provided the polyclonal goat antibodies).

Negative controls were tissues treated with the following: rabbit preimmune serum (Shriner's Hospital), normal rabbit serum (a gift from Biogenex), normal goat serum, and PBS (200 $\mu 1$ of each applied per contol slide). Infected and noninfected muscle tissue served as its own positive control for extracellular matrix proteins.

Primary antibodies were incubated at room temperature for 3 hours in a humidity chamber. Slides were then rinsed 2 times for 3 minutes each in PBS and the excess liquid wiped off. The secondary antibodies were stored in the dark at $4^{\circ} \mathrm{C}$. The secondary antibodies, affinity purified fluoroscein isothiocyanate (FITC)-conjugated anti-rabbit IgG Sigma F-6005 (dilution 1:64) and Sigma F-0382 (dilution 1:40), and affinity purified 
(FITC)-conjugated anti-goat IgG Sigma F-7367 (dilution 1:64), were applied at $200 \mu$ l per slide. Secondary antibodies were incubated for 30 minutes at room temperature in a humidity chamber. Slides were then rinsed 2 times in PBS for 3 minutes each and the excess liquid wiped off. (Sigma F-6005 and F-7367 were the kind gift of the Research Unit, Shriner's Hospital. Sigma F-0382 was kindly provided by the Taylors).

The slides were mounted with glycerol:PBS (9:1) using $8 \mu 1$ per slide. The slides were stored in the dark at $4^{\circ} \mathrm{C}$ until ready to view. The slides were examined with a Zeiss fluorescence microscope using a filter appropriate for viewing fluorescein. The following microscope filters were used: exciter filter 450-490 angstroms, chromatic beam filter 510 angstroms, and the barrier filter 520 angstroms. Pictures were taken at magnifications of $100 \times$ and $200 \times$ using the automatic function for exposure time and the large field of view. Antisera and purification of Shriner's Hospital polyclonal antibodies. Rabbit antisera were raised against type VI collagen and a synthetic peptide which corresponds to an amino acid sequence from the carboxyl telopeptide of type XI collagen following conventional procedures. Polyclonal rabbit antibodies raised against type VI collagen were recovered during the passage of Serum No. 4104 through an affinity column of type VI collagen which bound the Bound-Fraction to type VI collagen and eluted the Unbound-Fraction (personal communication Dr. Huey-Ju Kuo).

Shriner's Hospital, polyclonal rabbit antibody, Serum No. 4876 was raised against a synthetic peptide. The amino acid sequence of the synthetic peptide was taken from the carboxyl telopeptide of the $\alpha 1$ chain of type XI collagen. The first six amino acids of the peptide are identical in the $\alpha 2(\mathrm{XI})$ and the $\alpha 1(\mathrm{~V})$ chain. Therefore, the polyclonal antibody, Serum No. 4876, also recognizes type V collagen. The cross-reaction of Serum No. 4876 with type XI collagen and type V collagen has been confirmed by western blotting (personal communication Dr. Julia Thom-Oxford). 


\section{RESULTS}

\section{ELECTRON MICROSCOPY}

Electron micrographs of the nurse cell capsule show the expected division between an inner and outer region based upon the presence of many compacted and banded fibrils within the outer region and fibrils mixed with amorphous material within the inner region. These fibrils are within the expected size range $(16$ to $500 \mathrm{~nm})$ reported for the diameter of the fibrillar collagens type I and type III (Trelstad and Silver 1981, Piez and Reddi 1984). However, the identity of collagen types can not be determined solely by the banding pattern or the diameter of the fiber (Trelstad and Silver 1981).

Figure 4 shows an electron micrograph of the nurse cell capsule. Banded and compacted fibrils lie within the capsule. There appears to be a meshlike structure of fibrils throughout the capsule. In the outer region, these fibrils appear compacted and run parallel to one another. There are also fibers that appear to run perpendicular to the clusters of banded fibrils. The capsule is more amorphous as it nears the interface with the altered sarcoplasm surrounding the $\mathrm{L} 1$. In some regions, extensions of sarcoplasm appear to penetrate the capsule.

Electron micrographs of the encysted L1 show many small fibrils and/or filaments in the cuticle, hypodermis, and muscular layer. Some of the fibrils appear to have bands characteristic of the fibrillar collagens. Figure 5 shows an electron micrograph of an infective muscle stage $\mathrm{L} 1$. 

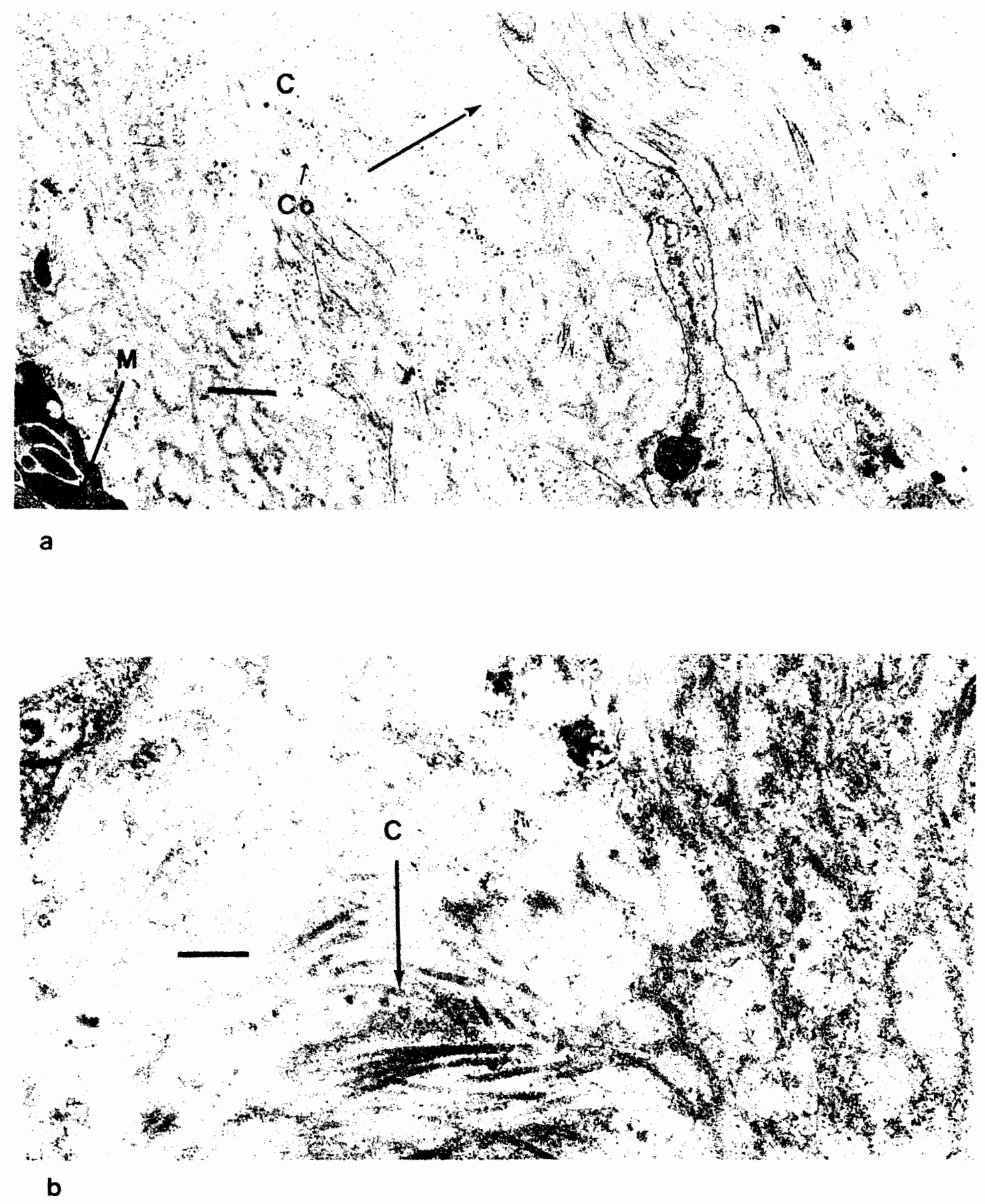

Figure 4. High power electron micrograph of the nurse cell capsule. (a) $17,600 \times$ magnification. Note the banded, compacted fibrils $(\mathrm{Co})$ within the outer region that lie in parallel. (b) 56,000× magnification. The capsule (C) is heterogenic with banded fibrils in the outer and inner regions. Matrix (M) of altered sarcoplasm. (a) $\mathrm{bar}=570 \mathrm{~nm}$, (b) bar $=180 \mathrm{~nm}$. 


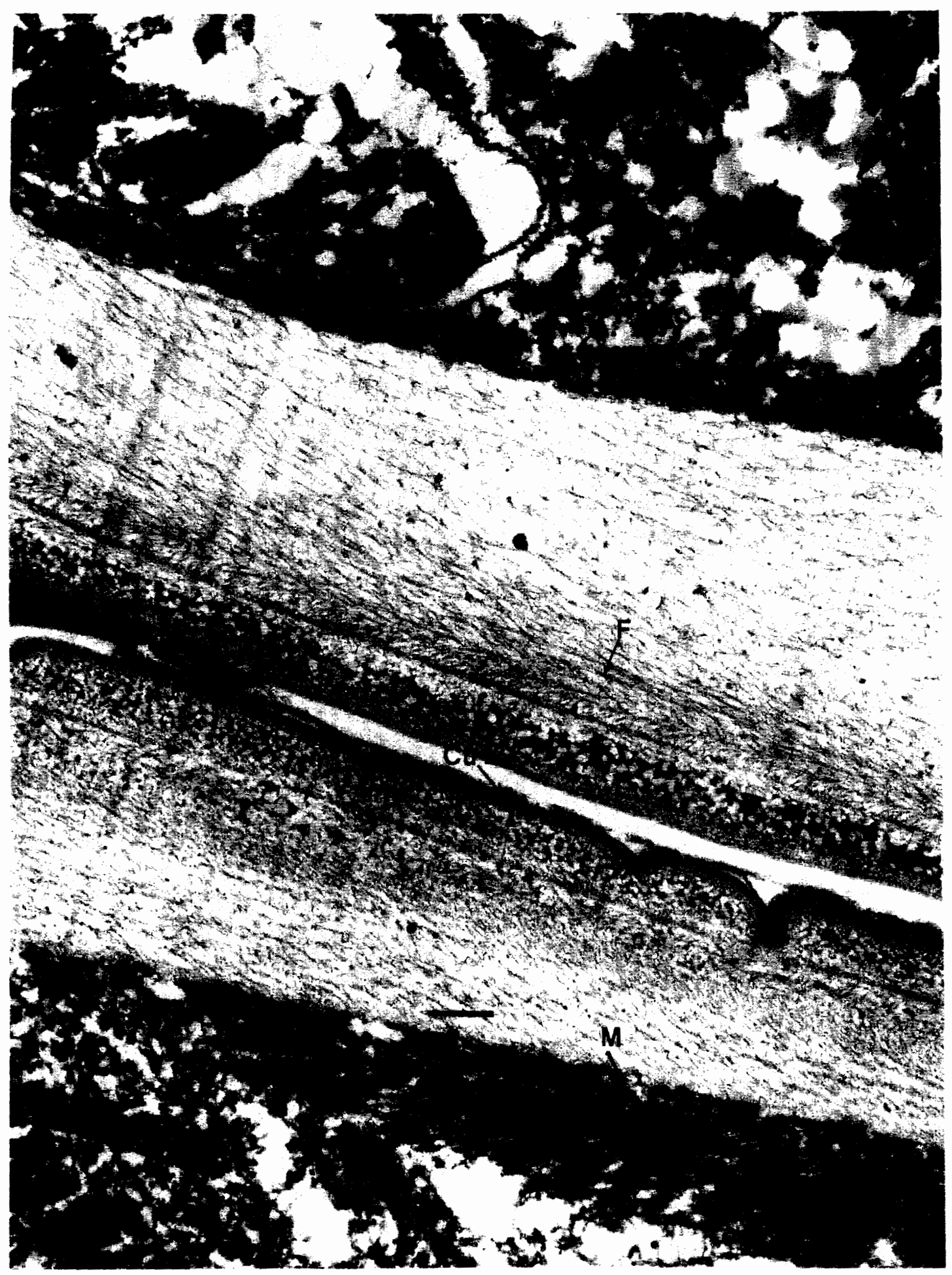

Figure 5. Electron micrograph of infective muscle stage L1. Microfibrils (F) are reported within the cuticle $(\mathrm{Cu})$, hypodermis, and near the muscle (M) layer of the nematode. Magnification 36,680×, bar $=272 \mathrm{~nm}$. 
Collagen polypeptides recovered from pepsin digestion of isolated nurse cells were characterized by SDS-polyacrylamide gel electrophoresis under reduced and non-reduced conditions and compared to authentic type VI collagen chains and the $\alpha 1 \alpha 2 \alpha 3$ chains of type XI collagen. Figure 6 shows the results of SDS-page of the nurse cell-pepsin digestion under reduced conditions on a $8.5 \%$ gel. TableI summarizes the results and the interpretation of the SDS-page fragments in tabular form.

Pepsin digestion of the nurse cell yielded resistant triple helical alpha chain fragments which co-migrated on SDS-polyacrylamide gels with known $\alpha 1 \alpha 2 \alpha 3$ chains of type XI collagen under both reduced and non-reduced conditions. This confirmed the presence of the fibrillar class of collagens within the nurse cell capsule. This is shown in Figure 6.

A large intense band consistently co-migrated with the $\alpha 3(\mathrm{XI})$ chain indicating the presence of more than one alpha chain migrating to that position. As previously stated, the $\alpha 1$ (I), $\alpha 1$ (III) reduced, and the $\alpha 1$ (II) chains are known to co-migrate with the $\alpha 3$ (XI) chain marker.

Additionally, a faint band migrated with slightly greater mobility than the $\alpha 3$ (XI) marker. This band, seen in lane 4 of Figure 6 , is consistent with the presence of an $\alpha 2(\mathrm{I})$ fragment. However, this band was not consistently seen in all trial gels. Under nonreduced conditions, a large band was seen to slowly enter the gel and may contain the disulfide-bonded trimers of types III, IV, and VI collagen. Also, as noted in Table I, under non-reduced conditions some sample material did not migrate away from the wells.

A distinct single band, seen in lanes 3 and 4 of Figure 6, co-migrated with the $\alpha 1$ (XI) chain which suggests the presence of the $\alpha 1(\mathrm{~V})$ chain but this was not consistently seen in all trial gels. A faint chain co-migrated with the $\alpha 2(\mathrm{XI})$ marker, also supporting the presence of type $\mathrm{V}$ collagen. However, this band was not consistently seen in all trial gels. 


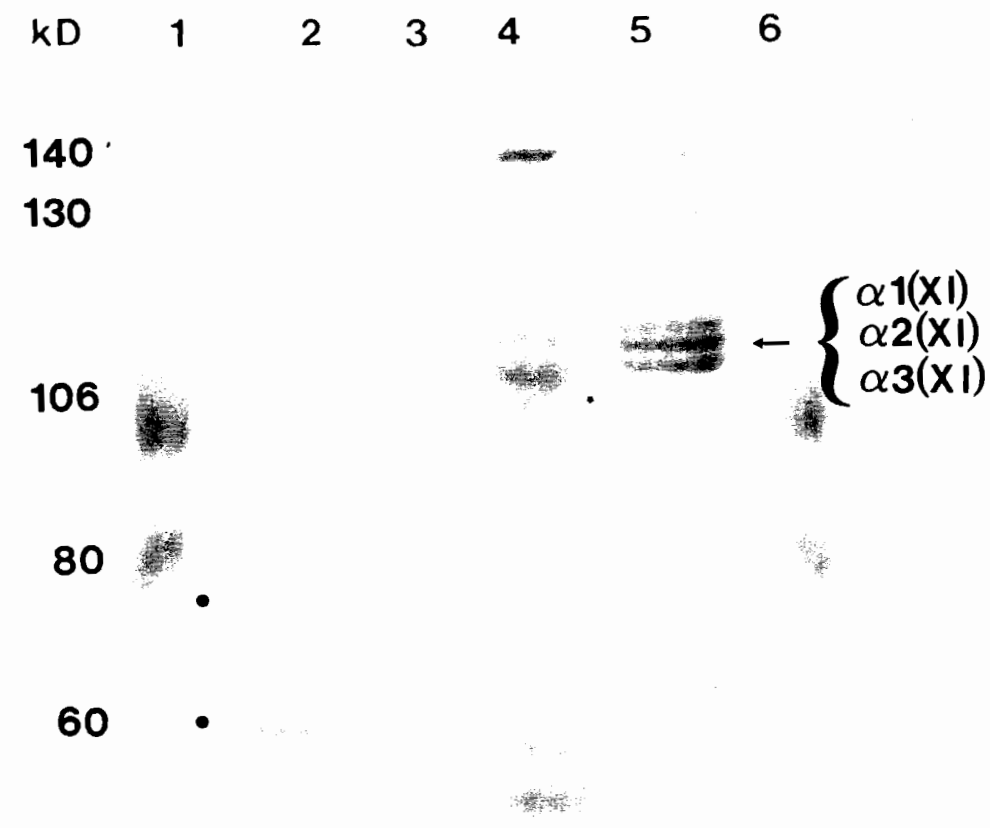

49.5

32.5

Figure 6. Characterization of the collagens of the nurse cell capsule by SDS-page of pepsin resistant fragments in a $8.5 \%$ reduced gel. Lanes 1 and 6, Bio-Rad prestained low molecular weight markers. Lane 2, authentic type VI collagen. Lane 3, pepsin digested nurse cell. I ane 4, pepsin digested nurse cell (visible host debris was removed by pipetting prior to pepsin digestion). Lane $5, \alpha 1 \alpha 2 \alpha 3$ marker of type XI collagen. $\bullet$ denotes major bands of type VI collagen in Lane 2 . denotes a possible $\alpha 2$ (I) chain in lane 4. 
Type II and type XI collagen are known to be cartilage specific (Mendler et al. 1989) and are not likely contaminants during nurse cell-pepsin digestion due to the repeated washing treatment to remove host debris.

Under reduced conditions, the nurse cell-pepsin digestion yielded fragments within the appropriate molecular weight range (130-140 kD and 160-180 kD) for the $\alpha 1$ (IV), $\alpha 2$ (IV), and P1 fragment of laminin. Similarly, the nurse cell-pepsin digestion yielded fragments within the molecular weight range for the $\mathrm{P} 2$ fragment of laminin $(50 \mathrm{kD})$ and the denaturation products of the $\alpha 1$ (IV) 140 chain ( $95 \mathrm{kD}$ and $70 \mathrm{kD}$ ). See lanes 2, 3, and 4 of Figure 6.

Similar electrophoretic mobility patterns of pepsin resistant fragments were observed between authentic type VI collagen and the nurse cell-pepsin digestion under reduced and non-reduced conditions. Under non-reduced conditions, in an $7.5 \%$ polyacrylamide gel (see Table I), a large band co-migrated with the type VI marker and barely entered the running gel. In an $8.5 \%$ gel under reduced conditions, two bands co-migrated to the same position. Pepsin digestion of the nurse cell, consistently yielded fragments within the molecular weight range of $40 \mathrm{kD}$ to $70 \mathrm{kD}$, under reduced conditions, which co-migrated with the authentic type VI collagen bands. See Figure 6.

Under nonreduced conditions, in an $7.5 \%$, gel a large major band of $330 \mathrm{kD}$ barely entered the gel. This band comigrated with the type VI marker, but, it is also within the range expected for the pepsin resistant fragment of laminin, molecular weight $260 \mathrm{kD}-350$ $\mathrm{kD}$ (Hakomori et al. 1984), before reduction.

Nurse cell-pepsin digestion samples obtained from the nurse cells of both mice and rats show the same pattern of migration of pepsin resistant fragments in a $5.0 \%$ polyacrylamide gel with respect to the known fibrillar collagen marker $\alpha 3(\mathrm{XI})$ and as compared to each other (see Table I). This suggests that the host response to the L1 is common to both species. 
TABLE I

\section{SUMMARY OF NURSE CELL PEPSIN RESISTANT \\ FRAGMENTS CHARACTERIZED \\ BY SDS-PAGE}

\section{Fragment Apparent Molecular Weight in $1.000(\mathrm{kD})$}

\section{5\% Reduced Gel}

$5.0 \%$ Reduced/Nonred. Gel

$7.5 \%$ Reduced/Nonred. Gel

\begin{tabular}{|c|c|c|c|c|c|}
\hline CMR & MNCR & MNCR & CMR/NR & $\underline{\mathrm{RNCNR}}$ & MNCR \\
\hline XI 140 & 140 & 140 & VI 384 & 206 & 203 \\
\hline XI 130 & 130 & 130 & XI 231 & 189 & 189 \\
\hline $\mathrm{XI} 112 *$ & 112 & 112 & XI 131* & - & 131 \\
\hline XI 107* & - & - & XI $117^{*}$ & - & - \\
\hline $\mathrm{XI} 102 *$ & 102 & 102 & XI $101^{*}$ & 101 & 101 \\
\hline VI 102 & 102 & 102 & - & 83 & 83 \\
\hline VI 95 & 95 & 95 & VI R 58 & - & 58 \\
\hline V1 78 & 78 & 78 & VI R 46 & - & 46 \\
\hline VI 60 & 60 & 60 & VI R 38 & - & 38 \\
\hline - & 69 & 69 & VI R 30 & - & 30 \\
\hline - & 56 & 56 & - & 35 & \\
\hline
\end{tabular}

\begin{tabular}{llll} 
CMR/NR & RNCNR & MNCR & RNCR \\
\cline { 1 - 2 } VI $\#$ & $\#$ & & \\
VI 330 & 330 & - & - \\
VI 236 & - & - & - \\
XI 194 & - & - & - \\
XI 189 & - & - & - \\
VI 179 & - & - & - \\
XI 141* & - & 141 & - \\
XI 134* & - & - & - \\
XI 128* & 128 & 128 & 128 \\
VI R 114 & - & 114 & 114 \\
VI R 86 & - & - & - \\
VI R 66 & 66 & 66 & 66 \\
- & 103 & 53 & 50
\end{tabular}

Key: (CMR) collagen marker reduced; (CMR/NR) collagen marker reduced/nonreduced; (MNCR) mouse nurse cell reduced; (RNCR) rat nurse cell reduced; (RNCNR) rat nurse cell nonreduced; * denotes $\alpha 1 \alpha 2 \alpha 3$ of (XI); \# denotes material left in well. 
In summary, SDS-page analysis of pepsin digested nurse cells is consistent with the presence of types I, III, IV, V, and VI collagens and laminin. However, the pattern of electrophoretic migration on a gel, while characteristic, is not sufficient proof of the identity of a fragment. Therefore, polyclonal antibodies specific for each type of molecule were used to identify and localize the extracellular matrix protein within the nurse cell capsule.

Indirect immunofluorescence, rather than western blot analysis, was used to identify the types of collagen and laminin present within the nurse cell capsule. Western blot analysis is inappropriate for the identification of collagens in the nurse cell-pepsin digestion. This is because the antigenic determinants of the native collagen molecules, with which antibody react, are digested away by pepsin treatment. The pepsin resistant fragments, characterized by SDS-page, consist of various lengths of the Gly-Xaa-Yaa repeats of their respective alpha chains.

The immunology of the collagens is discussed in Timpl (1984). Antigenic determinants of the triple helical portion of the native molecule require an intact triple helix. Denaturation of collagen separates the triple helix into constituent alpha chains and destroys the antigenic determinants of the triple helix. Antigenic determinants which are nonhelical in structure, either a terminal telopeptide or an interruption of the Gly-Xaa-Yaa repeat of the triple helix, are digested away by pepsin treatment.

\section{INDIRECT IMMUNOFLUORESCENCE PATTERN}

Table II provides a summary of the indirect immunofluorescence studies of nurse cells in infected skeletal muscle compared with noninfected muscles, using polyclonal antibodies against selected extracellular matrix proteins. Figures 7, 8, 9, and 10 show the tissue localization of the selected extracellular matrix proteins. Because immunostaining is a qualitative technique (Timpl 1984), the staining intensity does not necessarily correlate with the amount of a selected protein in a given tissue. 


\section{TABLE II}

TISSUE LOCALIZATION OF EXTRACELLULAR MATRIX PROTEINS

IN NORMAL AND INFECTED HOSTS USING

INDIRECT IMMUNOFLUORESCENCE

POLYCLONAL

ANTIBODY

TYPE I COLLAGEN

TYPE III COLLAGEN

TYPEIV COLLAGEN

GIBCO TYPE VI COLLAGEN

BOUND SERUM NO. 4104

SOUTHERN TYPE VI COL.

SERUM NO. 4876

LAMININ

TENASCIN

CONTROLS

UNBOUND SERUM NO. 4104 BIOGENEX RABBIT SERUM

PREIMMUNE RABBIT SERUM NEGATIVE GOAT SERUM

PBS
NURSE CELL-PARASITE COMPLEX

\section{CAPSULE MATRIX}

$+++$

$++$

$++$

$+++$

$+++$

$+++$

$-$

$++$

$-$
L1

-
$?$
-
$?$
-
+
++
-

$-$

$-$

$-$

$-$
HOST MUSCLE ENDOMYSIUM SARCOPLASM

Key. - negative response; ? questionable response;,,,++++++++++ intensity of positive response. 
All nurse cell capsules showed a strong positive reaction with the antibodies against the fibrillar collagens type I and III. While the reaction was dispersed throughout the entire capsule for both types of collagens, the intensity of labeling appeared strongest in the outer regions of the capsule. The pattern of labeling, had the appearance of dividing the capsule into distinct inner and outer regions in some of the nurse cells viewed. This labeling pattern corresponds well with the findings in the electron micrographs which showed many compacted banded fibrils in the outer region of the capsule.

The interstitial connective tissue of both normal and infected host muscle stained positive for both types I and type III collagen and served as a positive control for these antibodies. The muscle sarcoplasm of normal non-infected and infected hosts remained unlabeled for both types I and III collagen.

All of the anti-type VI antibodies stained the interstitial connective tissue of normal non-infected and infected muscle but not the muscle fiber's sarcoplasm. The labeling pattern for type VI collagen was consistent for both the anti-rabbit and anti-goat IgG secondary antibody systems employed. The host connective tissue served as a built in positive control for type VI collagen.

All of the polyclonal antibodies raised against type VI collagen exhibited very strong positive labeling throughout the entire breadth of the nurse cell capsule. Antibody directed against type VI collagen did not stain the L1 or the nurse cell's sarcoplasm.

The Shriner's Hospital polyclonal antibody to type VI collagen, Serum No. 4104 Bound-Fraction, has its own paired control in the polyclonal antibody, Serum No. 4104 Unbound-Fraction. The Unbound-Fraction of Serum No. 4104 contains all of the antibodies present in the rabbit serum except for the polyclonal antibody against type VI collagen. Unlike the Bound-Fraction which intensely stained the nurse cell capsule and host 
connective tissue, the Unbound-fraction failed to label the nurse cell and host tissue or produced a questionable response. The Bound-Fraction was specific for type VI collagen found in the nurse cell capsule and host connective tissue.

The antibodies directed against type IV collagen and laminin stained host connective tissue of noninfected and infected animals and served as a positive control. Polyclonal antibodies raised against the basement membrane proteins, type IV collagen and laminin, strongly labeled the nurse cell capsule in a diffuse pattern throughout the breadth of the capsule. There was no difference between the labeling pattern for type IV collagen and laminin, implying close association within the nurse cell capsule. The staining pattern of type IV collagen and laminin was similar to the pattern found for type VI collagen.

Antibody directed against tenascin produced negative results with the nurse cell complex and failed to label the L1, matrix, and capsule. Additionally, the antibody directed against tenascin did not recognize epitopes in either the noninfected or infected host muscle sarcoplasm or connective tissue. This is consistent with previous findings regarding tenascin expression in adults and healed tissue (Chuong and Chen 1991).

The Shriner's Hospital polyclonal antibody, Serum No. 4876, recognizes the $\alpha 1(\mathrm{~V})$ chain of type $\mathrm{V}$ collagen and the $\alpha 1(\mathrm{XI})$ and $\alpha 2(\mathrm{XI})$ chains of type XI collagen. Type XI collagen, a normal component of cartilage, is an irrelevant collagen in normal muscle tissue. Type $\mathbf{V}$ collagen is a normal component of the connective tissue of muscle. Serum No. 4876 was used to localize type V collagen.

However, as discussed in Linsenmayer et al. (1993), because type V collagen is a core fibril, epitopes along the triple helical portion and the carboxyl terminal domain of type $\mathrm{V}$ collagen are masked. Therefore, immunostaining of type V collagen epitopes is difficult to obtain. Unmasking these epitopes requires a harsh tissue treatment: either fiber disruption or enzymatic treatment with collagenase specific to the interstitial collagens surrounding the core type $\mathrm{V}$ collagen fibril. Because the tissues were not pretreated with either disruption or 
enzymatic digestion, Serum No. 4876 was not able to react with the nurse cell complex or the host tissue.

Serum No. 4876, produced a strong positive reaction with the encysted Trichinella spiralis larvae. This indicates that Serum No. 4876 recognized the amino acid sequence of the carboxyl telopeptide and that this epitope was exposed. Serum No. 4876 failed to react with the nurse cell's altered sarcoplasm, nurse cell capsule, the host muscle sarcoplasm, and the surrounding host connective tissue.

The tissues treated with negative controls failed to stain any parasite or host structure. Preimmune rabbit serum, normal goat serum, Biogenex normal rabbit serum, and PBS were used as negative controls and showed that the observed staining patterns of the tested antibodies were not due to nonspecific mechanisms or autofluorescence. The tissues treated with negative controls required exposure times greater than 36 seconds in order to obtain a photograph. This is in contrast to tissue sections with positive results that were exposed between 6 and 25 seconds. 


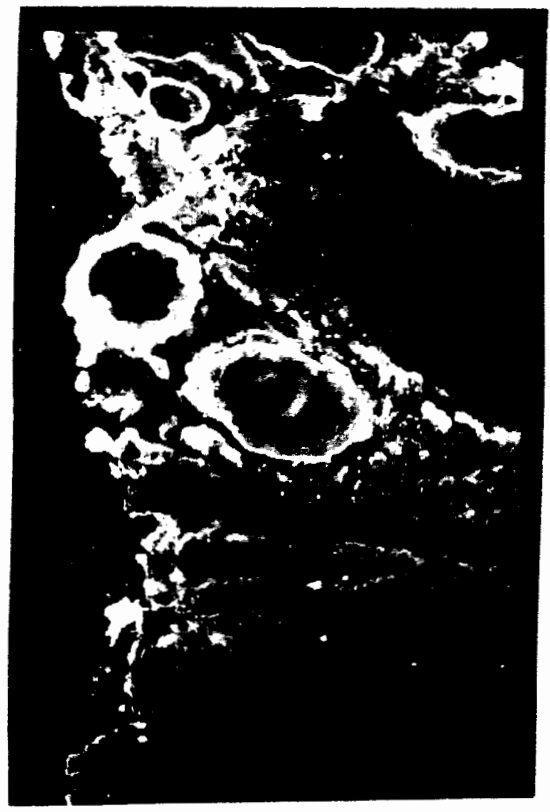

a

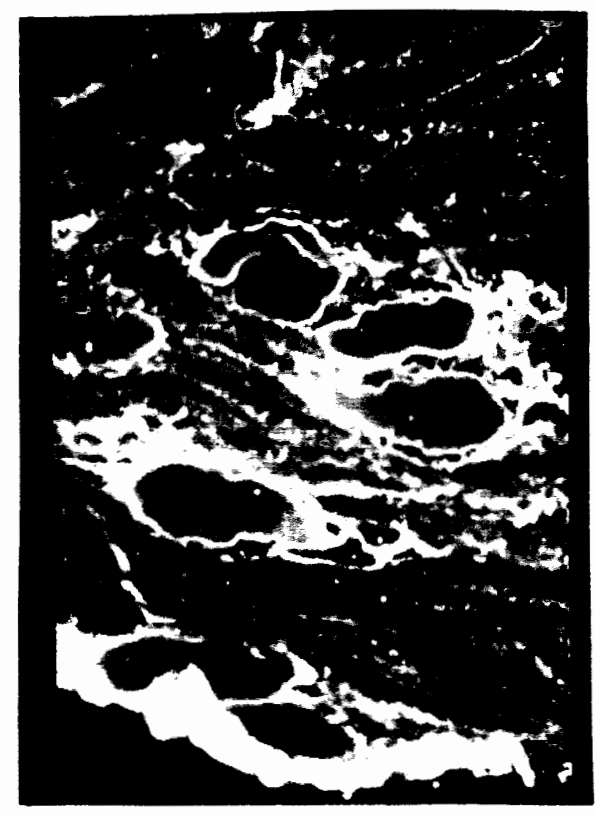

C

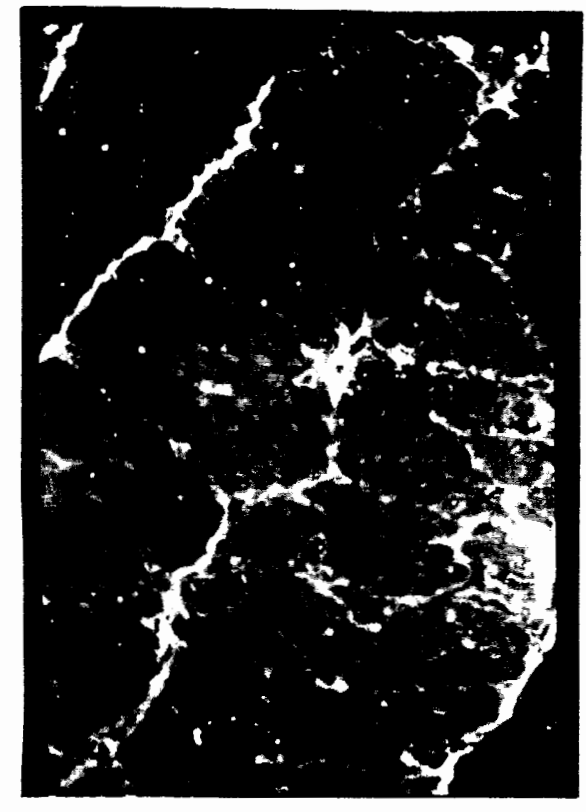

b

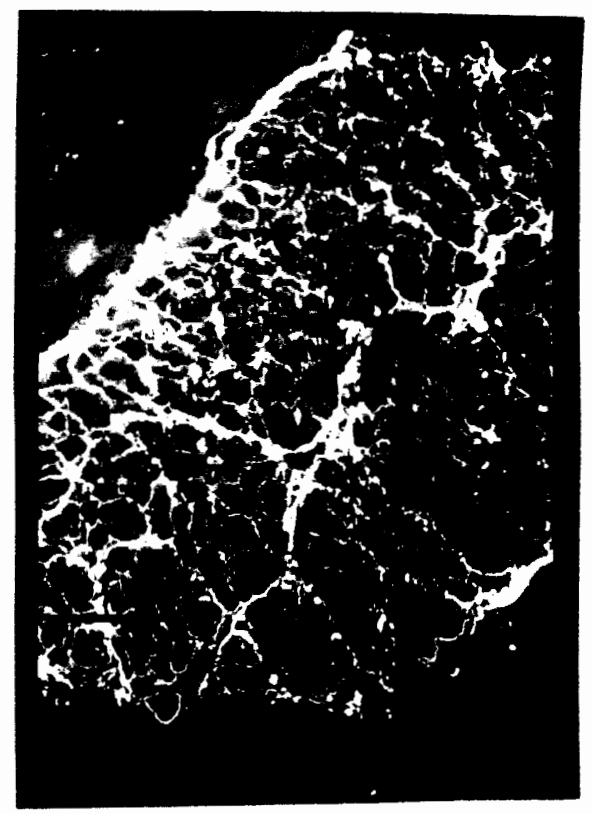

d

Figure 7. Immunolocalization of types I and III collagen in nurse cells and non-infected muscle. (a) Type I collagen occurs in the nurse cell capsule. (b) Type I collagen occurs within normal endomysium and perimysium. (c) Type III collagen occurs within the nurse cell capsule. (d) Type III collagen occurs within normal endomysium and perimysium. Antibodies to both type I and type III collagen stained the outer region of the capsule heavily. Magnification: $a, b$, c, and d 315x. Antibody dilution: a, b, c, and d 1:100. Bar $=32 \mu \mathrm{m}$. 


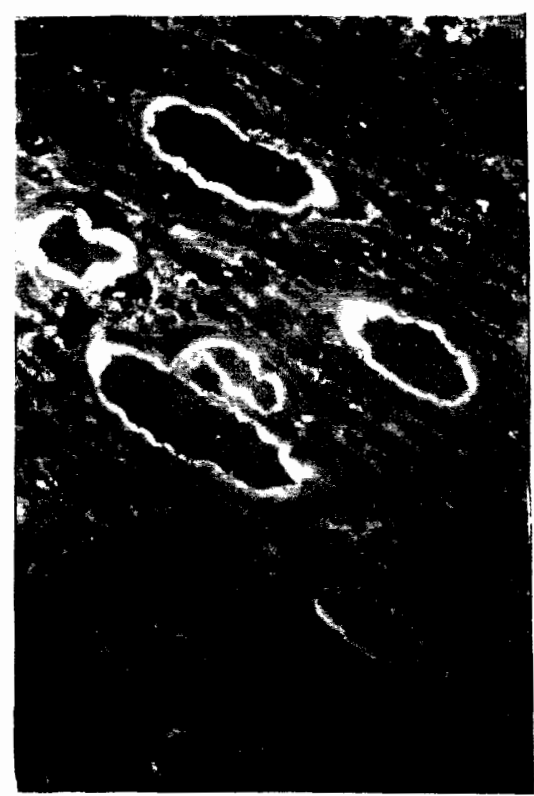

a

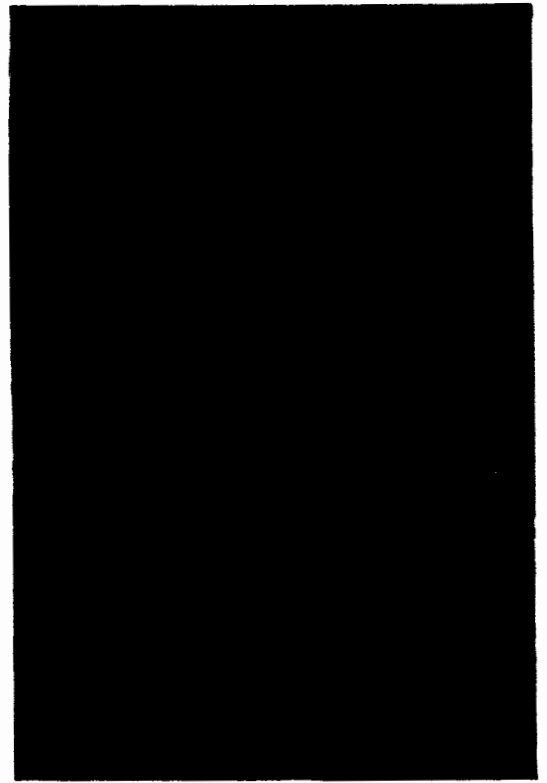

b



C

Figure 8. Immunolocalization of type IV collagen and laminin in nurse cells and non-infected muscle. (a) Type IV collagen localizes throughout the nurse cell capsule. (b) Laminin localizes throughout the nurse cell capsule. (c) Laminin and type IV collagen occur in host muscle connective tissue. Immunolocalization of laminin is representative of type IV collagen. Magnification: $a, b$, and c 315x. Antibody Dilution: $\mathrm{a}, \mathrm{b}$, and c 1:100. Bar $=32 \mu \mathrm{m}$. 


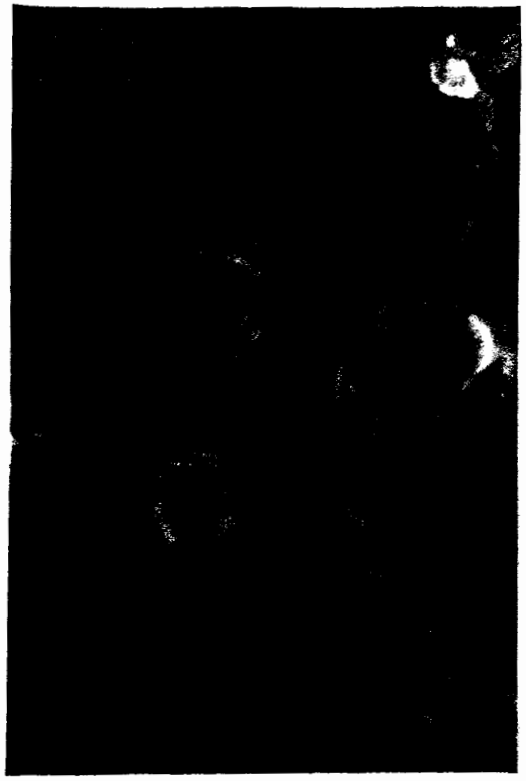

a

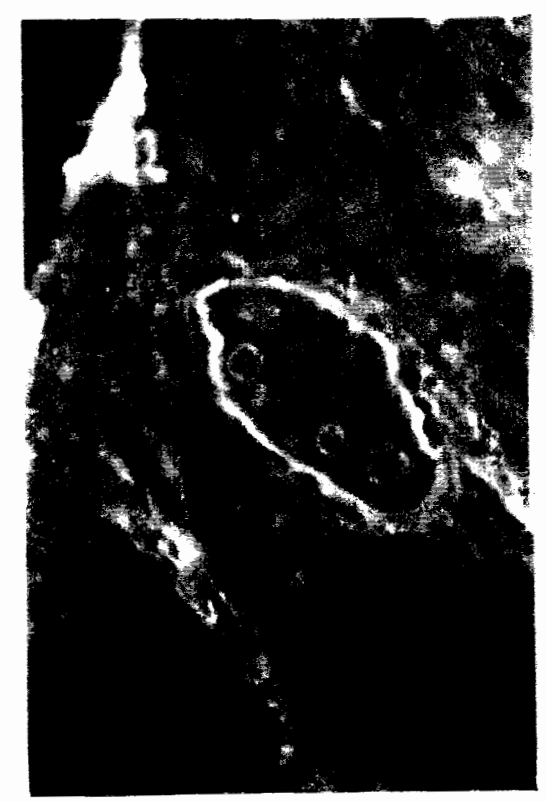

C

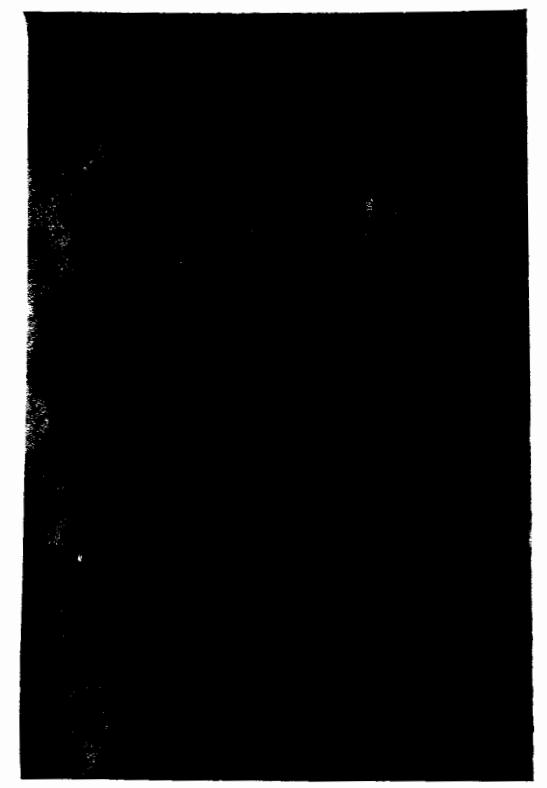

b



d

Figure 9. Immunolocaliztion of type VI collagen in nurse cells and non-infected muscle. (a) Anti-type VI collagen Serum No. 4104 Bound-fraction localizes to the nurse cell capsule. (b) Serum No. 4104 Unbound-fraction does not localize to the nurse cell. (c) Gibco BRL anti-type VI collagen localizes to the nurse cell capsule. (d) Goat anti-type VI collagen localizes to the connective tissue of normal muscle. Magnification: a, b, c, and d 315×. Antibody dilution: (a) 1:100, (b) 1:250, (c) 1:1000, (d) 1:1:100. Bar $=32 \mu \mathrm{m}$. 




a

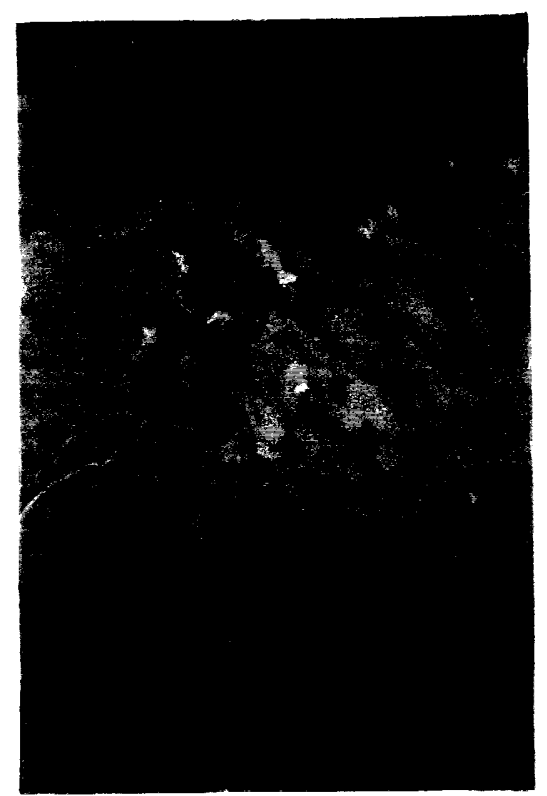

b

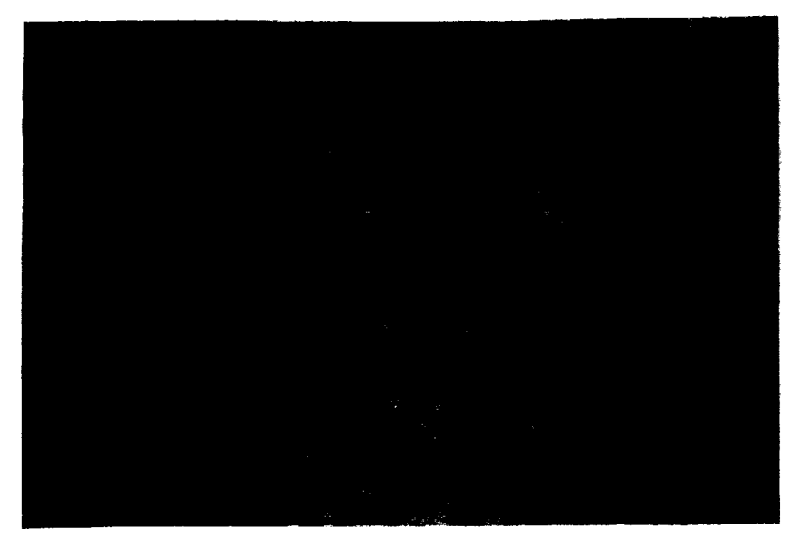

C

Figure 10. Immunolocalization of type V/XI collagen, tenascin, and negative controls in nurse cells and non-infected muscle. (a) Serum No. 4876 localizes to muscle stage L1. (b) Tenascin does not occur in normal host tissue. (c) Biogenex negative rabbit serum, negative controls do not stain the nurse cell or host connective tissue or muscle. Magnification: $a, b$, and $c$, 315×. Antibody dilution: (a) 1:25, (b) 1:500. Bar $=32 \mu \mathrm{m}$. 


\section{DISCUSSION}

\section{NURSE CELL CAPSULE}

Analysis of the nurse cell capsule by SDS-page of pepsin-resistant fragments and indirect immunofluorescence indicate that the capsule is a heterogenic structure. The nurse cell capsule is composed of both fibrillar and nonfibrillar collagens and laminin. The possibility that other extracellular matrix proteins are incorporated into the capsule can not be excluded by this analysis. This is because there are numerous molecules of the extracellular matrix, such as proteoglycans, elastin, or fibronectin, which were not selected for study.

In the nurse cell capsule, the fibrillar and nonfibrillar collagens, type I, type III, type IV, and type VI are indicated by both polyclonal antibody detection using indirect immunofluorescence and the results of SDS-page. The presence of type V collagen, within the nurse cell capsule, is clearly indicated by the results of SDS-page.

The immunofluorescence pattern, indicating types I, III, IV, and VI collagens and laminin throughout the nurse cell capsule, is consistent with the results of Bruce (1970). His microscopy surveys using histochemical methods found that the capsule contained collagen and stained P.A.S. positive. Type VI collagen and the basement membrane proteins, type IV collagen and laminin, are known to be P.A.S. positive (Padykula 1988, Spiro et al. 1992). Since all collagens contain varying amounts of carbohydrate, and are glycoproteins (Goldberg and Rabinovitch 1988), they stain P.A.S. positive.

While Bruce (1970) felt that the collagen of the nurse cell capsule did not show the axial banding of "true" collagen, the electron micrographs of Figures 4 and 5 show fibrils with a banding pattern reminiscent of collagen. The failure of Bruce (1970) to see 
periodicity in the collagen could be due to several factors. As discussed in Goldberg and Rabinovitch (1988), in cases where there is no apparent periodicity, the collagen may have aggregated randomly, it may be basement membrane collagen, or the material may be mostly proteoglycan or glycoprotein.

The presence of types I, III, IV, V, and VI collagens, within the nurse cell capsule, is also consistent with the work of Ritterson (1966). He concluded that the capsule was composed of collagen since it could only be completely digested with collagenase.

The heterogenic nature of the capsule is indicated by the presence of more than one type of collagen and laminin. The electron micrographs show many banded fibrils compacted into the outer region of the capsule. This corresponds to the results of indirect immunofluorescence for types, I, III, and VI collagens which stained heavily in the outer region. The close association of various types of collagens, as shown by indirect immunofluorescence, may indicate the formation of heterotypic fibrils or, more simply, proximity with one another.

Heterotypic fibrils of greater than one collagen type are known to exist in tissues. Types I and III collagen are an example of such a copolymerization event (Keene et al. 1987). Type VI collagen is known to weave among banded type I and III collagens in an independent network (Sakai et al. 1986). Type VI collagen may form bridges between the major fibrils and have an interconnecting role (Rabanus et al. 1991). Type V/XI collagen forms a core fibril around which other interstitial collagens aggregate and has chains which can be assembled into a variety of native heterotrimeric molecules (Mayne et al. 1993).

The possibility that the specific polyclonal antibodies cross react between collagen species is not a factor. All of the polyclonal antibodies, used in this study, have been affinity purified against irrelevant collagens to remove cross reactive antibodies and their specificity assessed during manufacture. Double immunofluorescent staining would be 
helpful in order to resolve the structural relationships between the various collagens and laminin.

The accumulation of extracellular material around the infected host muscle fiber could provide benefits for the $\mathrm{L} 1$ and its host. The mix of fibrillar and nonfibrillar collagen types may preserve the functional integrity of the nurse cell by providing mechanical support and protection from the host immune system. The capsule appears to protect the LI from the immune system (Wassom 1993) and shelter it from the stress associated with muscle contraction (Stewart and Giannini 1982).

Type I collagen, type III collagen, and type V collagen are known for their role in the wound healing (Goldberg and Rabinovitch 1988, Hurme et al. 1991, Hering et al. 1983, Narayanan et al. 1983). In the healing of muscle wounds (Hurme et al. 1991), type III collagen appears early and confers flexibility and plasticity to the connective tissue scar. Type I collagen, is synthesized later in the process of healing muscle wounds and provides tensile strength (Lehto et al. 1985). Therefore, type I and type III collagen may secure the environment of the L1 from mechanical disruption, but allow transmission of contractile force to other fibers across the injured cell. In this way, the whole muscle retains some ability to function.

Angiogenesis may be enhanced by the production of type I and type $V$ collagens for the nurse cell capsule. The newly synthesized extracellular matrix proteins may provide a favorable change in the extracellular environment and a pathway for proliferating and migrating endothelial cells. Type I collagen promotes capillary tube formation by endothelial cells of the microvasculature (Jackson et al. 1992). Hering et al. (1983) showed that an increase in type $\mathrm{V}$ collagen parallels an increase in capillary development. Therefore, type $\mathrm{V}$ collagen may be associated with angiogenesis and have a role in endothelial cell migration. 
Type IV collagen and laminin are ubiquitous components of basement membranes (Timpl 1989). Both type IV collagen and laminin provide basement membranes with a scaffolding network and have cell binding capabilities. Their presence in the nurse cell capsule suggests that basement membrane functions of support, sieving, and cell regulation are taking place (Yurchenco et al. 1990).

After the use of reserved $\mathrm{L} 1$ glycogen stores and, possibly, muscle glycogen or myofibril proteins, the larvae require an influx of nutrients (Stewart and Giannini 1982). Nutrients are probably delivered via the circulatory rete to the equatorial region of the nurse cell capsule where it is thinnest (Baruch and Despommier 1991). Selective filtration probably takes place with nutrients entering, waste products exiting, and large macromolecules excluded (Stewart and Giannini 1982). This process may be facilitated by the basement membrane proteins type IV collagen and laminin.

Laminin and type IV collagen polymerization is calcium dependent (Timpl 1989). It has been suggested that binding of calcium ions by basement membrane proteins is required to prevent calcification of basement membranes (Engel et al. 1987). If this is true, laminin and/or type IV collagen polymerization may prevent the early calcification of the nurse cell by binding calcium released from the damaged muscle cell. Additionally, binding calcium may prevent its toxic effects (Cheville 1988) from further damaging the altered host sarcoplasm.

The presence of type VI collagen (Oono et al. 1993) and laminin (de Sousa et al. 1991), both noted for their adhesive properties, may ensure the proper interaction of cells during the formation of the nurse cell capsule and the circulatory rete.

The presence of normal connective tissue and basement membrane proteins within the nurse cell capsule suggest that it is formed from existing host connective tissue and de novo synthesis. This is consistent with previous theories, including those of Bruce (1970) and Teppema et al. (1973), which suggested that the sarcolemma and basement membrane 
formed the basis of the nurse cell capsule.

The increased production of collagenous material around the infected muscle fiber is characteristic of a desmoplastic reaction to tissue injury (Noel et al. 1992). Desmoplasia results in the accumulation of abnormal amounts of fibrous tissue (granulation tissue). Granulation tissue is characterized by angiogenesis and the increased production of extracellular matrix (Chuong and Chen 1991, Cheville 1988), including type I, type III, and type V collagens over a period of 7 to 21 days (Hering et al. 1983). Type VI collagen is also found in connective tissue scars (Oono et al. 1993).

Cells respond to sublethal injury with repair of their plasma membrane and increased basement membrane secretion (Martinez-Hernandez et al. 1983). This is a nonspecific response which causes a thickening of this structure. Muscle cells which do not repair breaks in their plasma membranes undergo necrosis and death (McNeil and Khakee 1992).

Repair of the sarcolemma and the deposition of basement membrane proteins (Karpati and Carpenter 1982), after penetration by the $\mathrm{L} 1$, is consistent with muscle's normal cellular response to sublethal injury. The synthesis of types I, III, IV, V, and VI collagens and laminin, which results in capsule production, may reflect a nonspecific host response to $L 1$ parasitism.

Formation of the nurse cell capsule and angiogenesis does coincide with beginning and duration of myositis (Stewart et al. 1972). However, this does not exclude the possibility that larva-specific antigens, or some other type of host response, induce the transformation of muscle cell to nurse cell.

\section{Type V/XI Collagen}

The results of SDS-page conflicted with the results of indirect immunofluorescence regarding the presence of type $\mathrm{V}$ and type XI collagens within the nurse cell capsule. Serum No. 4876 recognizes an amino acid sequence found in the carboxyl terminal domain of the $\alpha 1(\mathrm{XI}), \alpha 2(\mathrm{XI})$, and the $\alpha 1(\mathrm{~V})$ chains (personal communication, Dr. Julia Thom- 
Oxford). However, immunostaining with Serum No. 4876 failed to recognize any epitope within the nurse cell capsule even though the characterization of the collagens by SDS-page clearly indicated the presence of type $\mathrm{V}$ collagen.

Type XI collagen is cartilage specific (Mendler et al. 1989) and, therefore, not an expected component of the nurse cell. However, the presence of type $\mathrm{V}$ collagen is expected within normal connective tissue (Mayne et al. 1993), granulation tissue (Hering et al. 1983), and indicated for the nurse cell by SDS-page. Serum No. 4876's failure to recognize type $\mathrm{V}$ collagen within the capsule is probably due to the core position of type $\mathrm{V}$ collagen in assembled fibrils and masking of its carboxyl terminal domain's epitopes.

As discussed in Linsenmayer et al. (1993), unless a tissue is harshly treated by either disruption of the fibril or enzymatic digestion with collagenase specific to the interstitial collagens types I, II , or III, many of the epitopes on type V collagen are unavailable for bonding with antibody.

Interestingly, the antibody, Serum No. 4876, did recognize a component of the firststage larvae. It is impossible to say whether this is type V collagen, type XI collagen, or a nematode-specific collagen. As discussed in Cox (1992), many nematode collagen genes and the biochemical nature of their proteins have been identified. In nematodes, there are between 20 and 150 collagen gene families which code for both fibrillar and nonfibrillar collagens. There are 16 identified cuticle collagens characterized by their small uniform size and extensive disulfide cross links. Furthermore, the nematodes have a highly conserved carboxyl terminal domain, designated domain $\mathrm{E}$, which is present in the mature extracellular protein. Like its counterpart in vertebrate collagens, this region is thought to function in the association of alpha chains into the triple helix and collagen monomers into fibers.

There is experimental evidence that the structure of invertebrate fibrillar collagens are highly homologous to vertebrate collagens (van der Rest and Garrone 1991) and that these 
similarities are reflected at the gene level (Vuorio and De Crombrugghe 1990, Cox 1992). Studies on sponge fibrillar collagen (Exposito and Garrone 1990) show greater structural homology with vertebrate type XI collagen than any other type. Both sponge fibrillar collagen (Exposito and Garrone 1990) and vertebrate type XI collagen (Mendler et al. 1989) have extremely thin fibrils with a diameter of approximately $20 \mathrm{~nm}$ and high conservation of the primary sequence of their carboxyl terminal domains (Exposito and Garrone 1990).

Type XI collagen is considered a primitive collagen and may have an ancestral structural function or serve as an axial template (Exposito and Garrone 1990). Additionally, the fibrillar collagen genes have evolved very little during evolution (Exposito and Garrone 1990). If a mammal and a nematode, which are distant in evolution, were to share a collagen, it would most likely be a more primitive collagen.

The localization of Serum No. 4876 in first-stage larvae of Trichinella spiralis is consistent with the evidence presented by Exposito and Garrone (1990) regarding type XI collagen in primitive invertebrates. The amino acid sequence recognized by Serum No. 4876 may be conserved in both primitive invertebrates and vertebrates. Type V/XI collagen may fulfill the same function in these evolutionary distant organisms. Namely, the limitation of lateral growth of fibrils and regulation of fibrillogenesis (Mendler et al. 1989).

\section{Tenascin}

The results of indirect immunofluorescence tests indicate that tenascin is not present in normal non-infected adult muscle, the structurally complete nurse cell, or the infected host muscle of long-term infections. Polyclonal antibody directed against tenascin was used to detect wound healing events associated with the nurse cell. Tenascin is a glycoprotein reported to play a role in organizing new extracellular matrix and is expressed during embryonic morphogenesis, tissue regeneration (Chuong and Chen 1991), and malignancy (Riedel et al. 1992). 
Chuong and Chen (1991) report that tenascin expression is induced in the mesenchymal components of a variety of injured tissues. They report both a temporal and spatial pattern of expression. During peak levels of expression, tenascin is enriched in granulation tissue with a distribution that corresponds to the middle of newly formed collagen fibrils. They suggest that tenascin's domains have properties of growth factors, polymer formation, and adhesion molecules. Tenascin disappears completely once the wound is healed.

Tenascin is also re-expressed in the stroma of tumors (Natali and Zardi 1989, Chuong and Chen 1991). Dvorak (1986), hypothesized that tumor stroma reflect wounds that do not heal. He suggests that injuries caused by a tumor induce a host tissue response represented by tumor stroma. Unlike growing tumors, neither the encysted first-stage larvae nor the completed nurse cell appear to cause further host tissue injury.

The absence of tenascin indicates that a structurally complete nurse cell is a stable entity which does not continue to grow and injure host tissue. However, expression of tenascin is likely to occur at the site of muscle penetration and during the formation of the nurse cell. Injury to host tissue is likely to occur during the exponential growth phase (Stewart and Giannini 1982, Despommier et al. 1975). Development of the nurse cell is a sequelae to tissue injury with the formation of new connective tissue. 


\section{REFERENCES}

Adachi, E., and T. Hayashi. 1986. In vitro formation of hybrid fibrils of type V collagen and type I collagen. Limited growth of type I collagen into thick fibrils by type $\mathrm{V}$ collagen. Connective Tissue Research 14: 257-266

Ashhurst, D.E., Bland, Y.S., and J.R. Levick. 1991. An immunohistochemical study of the collagens of rabbit synovial interstitium. Journal of Rheumatology 18(11): 16991672

Bailey, A.J., Shellswell, G.B., and V.C. Duance. 1979. Identification and change of collagen types in differentiating myoblasts and developing chick muscle. Nature 278: 67-69

Baruch, A., and D. Despommier. 1991. Blood vessels in Trichinella spiralis infections: A study using vascular casts. Journal of Parasitology 77(1): 99-103

Becker, J., Schuppan, D., Rabanus, J.P., Gelderblom, H.R., and P. Reichart.. 1991. Immunoelectron microscopy shows an atypical pattem and a quantitative shift of collagens type I, III, and VI in oral Kaposi's sarcoma of AIDS. Virchows Arch. A. Pathology Anat. Histopathology 419(3): 237-244

Bruce, R.G. 1970. The structure and composition of the capsule of Trichinella spiralis in host muscle. Parasitology 60: 223-227

Bruckner, P., and D. Prockop. 1981. Proteolytic enzymes as probes for the triple-helical conformation of procollagen. Analytical Biochemistry 110: 360-368

Bruschi, F., Solfanelli, S., and R. Binaghi. 1992. Trichinella spiralis: Modifications of the cuticle of newborn larva during passage through the lung. Experimental Parasitology 75: $1-9$

Campbell, W.C. 1983. In Trichinella and Trichinosis. W.C. Campbell (ed.). Plenum Press, New York/London, p. 425-444

Campbell, W.C., and A.C. Cuckler. 1964. Effect of thiabendazole upon the enteral and parenteral phases of trichinosis in mice. Journal of Parasitology 50: 481-488

Capo, V.A., Despommier, D.D., and D.S. Silberstein. 1984. The site of ecdysis of the L1 larva of Trichinella spiralis. Journal of Parasitology 70: 992-994

Chandler, A. and C.P. Read. 1964. Trichuris, Trichinella, and their allies. In Introduction to Parasitology. A. Chandler and C. P. Read (eds.). John Wiley and Sons, New York, p. 399-416 
Chanoki, M., Ishii, M., Fukai, K. et al. 1991. Immunohistochemical localization of type I, III, IV, and VI collagens and laminin in neurofibroma and neurofibroscaroma. American Journal Dermatopathology 13(4): 365-373

Cheville, N.F. 1988. Introduction to Veterinary Pathology. Iowa State University Press. Ames, Iowa, p. 15, 60, 495

Chuong, C. and H. Chen. 1991. Enhanced expression of neural cell adhesion molecules and tenascin (cytotactin) during wound healing. American Journal of Pathology 138: $427-440$

Colombatti, A., Bonaldo, P., and F. Bucciotti. 1992. Stable expression of chick type-VI collagen $\alpha 1, \alpha 2$, and $\alpha 3$ cDNAs in murine NIH/3T3 cells. European Journal of Biochemistry 209: 785-792

Cox, G. N. 1992. Molecular and biochemical aspects of nematode collagens. Journal of Parasitology 78(1): 1-15

de Sousa, M., Tilney, N., and J. Kupiec-Weglinski. 1991. Recognition of self within self: specific lymphocyte positioning and the extracellular matrix. Immunology Today 12(8): 262-266

Despommier, D.D. 1975. Adaptive changes in muscle fibers infected with Trichinella spiralis. American Journal of Pathology 78: 477-496

Despommier, D.D. 1976. Musculature. In Ecological aspects of Parasitology, C.R. Kennedy (ed.). North Holland, Amsterdam, p. 269-285

Despommier, D.D. 1983. Biology. In Trichinella and Trichinosis. W.C. Campbell (ed.). Plenum, New York/London, p. 75-151

Despommier, D.D. 1990. Trichinella spiralis: the worm that would be virus. Parasitology Today 6: 193-196

Despommier, D.D. 1993. Trichinella spiralis and the concept of niche. Journal of Parasitology 79(4): 472-482

Despommier, DD., Aron, L. and L. Turgeon. 1975. Trichinella spiralis: Growth of the intracellular muscle larva. Experimental Parasitology 37: 108-116

Despommier, D.D., Gold, A., Buck, S., et al. 1990. Trichinella spiralis: Secreted antigen of the infective L1 larva localizes to the cytoplasm and nucleoplasm of infected host cells. Experimental Parasitology 71: 27-38

Despommier, D.D., Sukhdeo, M., and E. Meerovitch. 1978. Trichinella spiralis: site selection by the larva during the enteral phase of infection in mice. Experimental Parasitology 44: 209-215

Despommier, D.D, Symmans, W., and R. Dell. 1991. Changes in nurse cell nuclei during synchronous infection with Trichinella spiralis. Journal of Parasitology 77(2): 290295 
Doane, K.J., Yang, G., and D.E. Birk. 1992. Corneal cell-matrix interactions: type VI collagen promotes adhesion and spreading of corneal fibroblasts. Experimental Cell Research 200(2): 490-499

Dvorak, H. 1986. Tumors: Wounds that do not heal. New England Journal of Medicine 315: $1650-1659$

Engel, J., Furthmayr, H., et al. 1985. Structure and macromolecular organization of type VI collagen. Annals New York Academy of Sciences 460: 25-37

Engel, J., Taylor, M., Paulsson, M., Sage, H., and B.L. Hogan. 1987. Calcium binding domains and calcium-induced conformational transition of SPARC/ BM 40/ Osteonectin, and extracellular glycoprotein expressed in mineralized and nonmineralized tissues. Biochemistry 26: 6958-6965

Eyre, D., Wu, J.J., and D. Woolley. 1984. All three chains of $1 \alpha 2 \alpha 3 \alpha$ collagen from hyaline cartilage resist human collagenase. Biochemical and Biophysical Research Communications 118(3): 724-729

Exposito, J.Y. and R. Garrone. 1990. Characterization of a fibrillar collagen gene in sponges reveals the early evolutionary appearance of two collagen gene families. Proc. Natl. Acad. Sci. USA 87: 6669-6673

Furuto, D., Gay, R., Stewart, T. et al. 1991. Immunolocalization of types V and XI collagen in cartilage using monoclonal antibodies. Matrix 11: 144-149

Ganong, W.F. 1989. Review of Medical Physiology. Appleton \& Lange, East Norwalk, CT, p. 398-407

Goldberg, B. and M. Rabinovitch. 1988. Connective tissue. In Cell and Tissue Biology. A Textbook of Histology. L. Weiss (ed.). Urban and Schwarzenburg, Baltimore, p. $157-168$

Hakomori, S., Fukuda, M., Seikiguchi, K., and W. Carter. 1984. Fibronectin, laminin, and other extracellular glycoproteins. In Extracellular Matrix Biochemistry. K.A. Piez and A.H. Reddi (eds.). Elsevier, New York, p. 229-275

Hay, E.D. 1981. Introduction. In Cell Biology of the Extracellular Matrix. E.D. Hay (ed.). Plenum Press, New York, p. 1-4

Hering, T.M., Marchant, R.E., and J.M. Anderson. 1983. Type V collagen during granulation tissue development. Exp. Mol. Pathol. 39:219-229

Hughes, W.L., and J.P. Harley. 1977. Trichinella spiralis: Taxes of first stage migratory larvae. Experimental Parasitology 42: 363-373

Humes, A.G., and R.P. Ackers. 1952. Vascular changes in the cheek pouch of the golden hamster during infection with Trichinella spiralis larvae. Anatomical Record 114: 103113

Hurme, T., Kalimo H., et al. 1991. Localization of type I and III collagen and fibronectin 
Hurme, T., Kalimo H., et al. 1991. Localization of type I and III collagen and fibronectin production in injured gastrocnemius muscle. Laboratory Investigation 64: 76-84

Jackson, C.J., Jenkins, K., and L. Schrieber. 1992. Possible mechanisms of type I collagen induced vascular tube formation. In Angiogeneis: Key Principles-ScienceTechnology-Medicine. R. Steiner, P.B. Weisz and R. Langler (eds.). Birkhauser Verlag, Basel, p. 198-204

Jasmer, D. 1990. Trichinella spiralis: Altered expression of muscle proteins in trichinosis. Experimental Parasitology 70: 452-465

Jasmer, D. 1993. Trichinella spiralis infected skeletal muscle cells arrest in G2/M and cease muscle cell expression. Journal of Cell Biology 121(4): 785-793

Karpati, G. and Carpenter, S. 1982. Micropuncture lesions of skeletal muscle cells: A new experimental model for the study of muscle cell damage, repair, and regeneration. In Disorder of the Motor Unit. D.L. Scotland (ed.). John Wiley \& Sons, New York, p. 517-533

Katsuda, S., Okada, Y.., Minamato, T. et al. 1992. Collagens in human atherosclerosis: Immunohistochemical analysis using collagen type-specific antibodies. Arterioscler. Thromb. 12(4): 494-502

Keene, D., Sakai, L., Bachinger, H., and R. Burgeson. 1987. Type III collagen can be present on banded collagen fibrils regardless of fibril diameter. Journal of Cell Biology 105: 2393-2402

Ko, R. C., Fan L., and D.L. Lee. 1992. Experimental reorganization of host muscle cells by excretory/secretory products of infective Trichinella spiralis larvae. Transactions of the Royal Society of Tropical Medicine and Hygiene 86: 77-78

Kozek, W. 1971. Light microscope study of the molting pattern in Trichinella spiralis. Journal of Parasitology 57(5): 1015-1028

Kuhn et al. 1985. Structure of type IV collagen. Annals New York Academy of Sciences 460: $14-24$

Laas, T. 1989. Electrophoresis in gels. In Protein Purification: Principles, High Resolution Methods, and Applications. J. Janson and L. Ryden (eds.). VCH Publishers Inc., New York, p. 349-375

Laemmli, U.K. 1970. Cleavage of structural proteins during the assembly of the head of bacteriophage T4. Nature 227: 680-685

Larsen, E., Stewart, G., and J. Niederkorn. 1991. Trichinella pseudospiralis overcomes innate resistance of the Chinese hamster to Trichinella spiralis. Parasitology 103: 465470

Lee, D.L., Ko, R.C., Yi, X.Y., and M.H. Yeung. 1991. Trichinella spiralis: antigenic epitopes from the stichocytes detected in the hypertrophic nuclei and cytoplasm of the parasitized muscle fiber (nurse cell) of the host. Parasitology 102: 117-123 
Lee, D.L., and R.R. Shivers. 1987. A freeze fracture study of muscle fibers infected with Trichinella spiralis. Tissue and Cell 19: 665-671

Lehninger, A.L. 1982. Principles of Biochemistry. S. Anderson and J. Fox (eds.). Worth Publishers, Inc., New York, p. 131, 688

Lehto, M., Duance, V., and D. Restall. 1985. Collagen and fibronectin in the effects of physical activity on the repair of the injured gastrocnemius muscle in the rat. Journal of Bone Joint Surg. 67B: 820

Linsenmayer, T.F. 1981. Collagen. In Cell Biology of Extracellular Matrix. E.D. Hay (ed.). Plenum Press, New York, p. 5-37

Linsenmayer, T., Gibney, E., Igoe, F., et al. 1993. Type V collagen: Molecular structure and fibrillar organization of the chicken a1(V) NH2-terminal domain, a putative regulator of corneal fibrillogenesis. Journal of Cell Biology 121(5): 1181-1189

Marinculic, A., Gamble, H., Zarlenga, D. et al. 1991. Characterization of a noncystforming isolate of Trichinella from a wild boar in Yugoslavia. Journal of Parasitology 77(2): $224-230$

Martinez-Hernandez, A. and P.S. Amenta. 1983. The basement membrane in pathology. Lab. Invest. 48: 656-677

Mayne, R., Brewton, R., Mayne, P., and J. Baker. 1993. Isolation and characterization of the chains of Type V/Type XI collagen present in bovine vitreous. Journal of Biological Chemistry 268(13): 9381-9386

McNeil, P., and R. Khakee. 1992. Disruptions of muscle fiber plasma membranes. American Journal of Pathology 140: 1097-1109

McNeil P., and S. Ito. 1990. Molecular traffic through plasma membrane disruptions of cells in vivo. Journal Cell Science 96: 549-556

Mendler, M., Eich-Bender, S., Vaughan, L., Winterhalter, K., and P. Bruckner. 1989. Cartilage contains mixed fibrils of collagen types II, IX, and XI. Journal of Cell Biology 108: 191-197

Miller, E.J. 1972. Structural studies on cartilage collagen employing limited cleavage and solubilization with pepsin. Biochemistry 11: 4903-4909

Miller, E.J. 1984. Chemistry of the collagens and their distribution. In Extracellular Matrix Biochemistry. K.A. Piez and A.H. Reddi (eds.). Elsevier, New York, p. 41-81

Miller, E.J. and S. Gay. 1987. The collagens: an overview and update. Methods in Enzymology 144D: 3-41

Miller, E.J. and R.K. Rhodes. 1982. Preparation and characterization of the different types of collagen. Methods in Enzymology 82A: 33-64 
Morris, N. P. and H.P. Bachinger. 1987. Type XI collagen is a heterotrimer with the composition $(1 \alpha 2 \alpha 3 \alpha)$ retaining non-triple-helical domains. Journal of Biological Chemistry 262(23): $11345-11350$

Morris, N.P., Watt, S.L., Davis J.M., and H.P. Bachinger. 1990. Unfolding intermediates in the triple helix to coil transition of bovine type XI collagen and human type V collagens $\alpha 1 \alpha 2$ and $\alpha 1 \alpha 2 \alpha 3$. Journal of Biological Chemistry 265(17): 10081-10087

Morrison, J.C., Rask, P., Johnson, E., and L. Deppmeier. 1990. Chondroitin sulfate proteoglycan distribution in the primate optic nerve head. Association for Research in Vision and Opthamology Spring Meeting, Sarasota, Florida, 1990

Narayanan, A.S., Engel, L.D., and R.C. Page. 1983. The effect of chronic inflammation on the composition of collagen types in human connective tissue. Collagen Rel. Research 3: 323-334

Natali, P., and L. Zardi. 1989. Tenascin: a hexameric adhesive glycoprotein. Int. J. Cancer 4: $66-68$

Noel A., Munuat, C., Boulvain, A., et. al. 1992. Modulation of collagen and fibronectin synthesis in fibroblasts by normal and malignant cells. Journal of Cellular Biochemistry 48: 150-161

Oono, T., Specks, U., Eckes, B., et al. 1993. Expression of type VI collagen mRNA during wound healing. Journal of Investigative Dermatology 100: 329-334

Otto, U., Odermatt, E., Engel, J., Furthmayr, H., and R. Timpl. 1982. Protease resistance and conformation of laminin. European Journal of Biochemistry 123: 63-72

Padykula, H. 1988. Histochemistry and Cytochemistry. In Cell and Tissue Biology. A Textbook of Histology. L. Weiss(ed.). Urban and Schwarzenburg, Baltimore, p. 99100

Panayotou, G. End, P., Aumailley, M., et al. 1989. Domains of laminin with growthfactor activity. Cell 56: 93-101

Piez, K.A. 1976. Primary Structure. In: Biochemistry of Collagen. G.N. Ramachandran and A.H. Reddi (eds.). Plenum Press, New York, p. 1-44

Piez, K.A, and A H. Reddi. 1984. Preface. In Extracellular Matrix Biochemistry. K.A. Piez and A.H. Reddi (eds.). Elsevier, New York, p. xii-xiv

Pozio, E., La Rosa, G., and P. Rossi. 1989. Trichinella Reference Center. Parasitology Today 5(6): 169-170

Purkerson, M., and D.D. Despommier. 1974. Fine structure of the muscle phase of Trichinella spiralis in the mouse. In Trichinellosis. C.W. Kim (ed.), Intext, New York, p. 7-23 
Rabanus, J.P., and H.R. Gelderblom. 1991. Distribution of collagens type V and VI in the normal human alveolar mucosa: an immunoelectronmicroscopic study using ultrathin frozen sections. Journal Periodontal Research 26(3): 138-143

Rao, C.N., Margulies, I.M.K., Goldfarb, R.H., et al. 1982. Differential proteolytic susceptibility of laminin alpha and beta subunits. Arch. Biochem. Biophys. 219: 6570

Reddi, A.H. 1984. Extracellular Matrix and Development. In Extracellular Matrix Biochemistry. K.A. Piez and A.H. Reddi (eds.). Elsevier, New York, p. 375-412

Riedl, St., Moller, P., Faissner A., and P. Schlag. 1992. Induction and altered distribution of tenascin in the basal lamina of colorectal adenomas and carcinomas. In Angiogenesis: Key Principles - Science - Technology - Medicine. R. Steiner, P.B. Weisz, \& R. Langer (eds.). Birkhauser Verlag, Basel p. 277-281

Ritterson, A.L. 1966. Nature of the cyst of Trichinella spiralis. Journal of Parasitology 52: $157-161$

Romanos, G., Schroter-Kermani, C., Hinz, N. and J. Bernimoulin. 1991. Immunohistochemical distribution of the collagen types IV, V, VI and glycoprotein laminin in the healthy rat, marmoset (Callithrix jacchus) and human gingivae. Matrix 11: $125-132$

Sakai, L., Keene, D., and E. Engvall. 1986. Journal of Cell Biology 103: 2499-2509

Sambrook, J., Fritsch, E.F., and T. Maniatis. 1989. Detection and analysis of proteins expressed from cloned genes. In Molecular Cloning: a laboratory manual. N. Ford (ed.). Cold Spring Harbor Laboratory Press, New York, p. 18.47-18.59

Schmidt, G.D., and L.S. Roberts. 1989. Orders Trichurata and Dioctophymata: Aphasmidian Parasites. In Foundations of Parasitology. D.K. Brake (ed.). Times Mirror/Mosby College Publishing, St. Louis, p. 416-427

Shuttleworth, C.A., Berry, L., and C.M. Kielty. 1992. Microfibrillar components in dental pulp: presence of both type VI collagen and fibrillin- containing microfibrils. Arch. Oral Biology 37(12): 1079-1084

Spiro, M.J., Kumar, B.R., and T.J. Crowley. 1992. Myocardial glycoproteins in diabetes: type VI collagen is a major PAS-reactive extracellular matrix protein. Journal of Molecular Cell Cardiology 24(4): 397-410

Sporn, M.B., and Roberts, A.B., Wakefield, L.M., and B. De Crombrugghe. 1987. Some recent advances in the chemistry and biology of transforming growth factorbeta. Journal Cell Biology 105: 1039

Stewart, G.L. 1983. Pathophysiology of the muscle phase. In Trichinella and Trichinosis. W.C. Campbell (ed.). Plenum, New York, p. 241-264

Stewart, G.L., Charniga, L., and R.B. Boley. 1972. Myositis in mouse trichinellosis. Journal of Parasitology 68:730-732 
Stewart, G. and S. Giannini. 1982. Sarcocystis, Trypanosoma, Toxoplasma, Brugia, Ancylostoma, and Trichinella spp.: A review of the intracellular parasites of striated muscle. Experimental Parasitology 53: 406-447

Stewart, G.L., and C.P. Read. 1972a. Ribonucleic acid metabolism in mouse trichinosis. Journal of Parasitology 58: 252-256

Stewart, G.L. and C.P. Read. 1972b. Some aspects of cyst synthesis in mouse trichinosis. Journal of Parasitology 58: 1061-1064

Stewart, G.L. and C.P. Read. 1973a. Changes in RNA in mouse trichinosis. Journal of Parasitology 59: 997-1005

Stewart, G.L. and C.P. Read. 1973b. Deoxyribonucleic acid metabolism in mouse trichinosis. Journal of Parasitology 59: 264-267

Stewart, G.L. and C.P. Read. 1974. Studies on biochemical pathology in trichinosis. 1. Changes in myoglobin, free creatine, phosphocreatine, and two protein fractions of mouse diaphragm muscle. Journal of Parasitology 60(6): 996-1000

Takahashi, Y., Mizuno, N., Shimazu, K., and T. Araki. 1992. Ultrastructure, antigenicity, and histochemistry of the stichocyte granules of adult Trichinella spiralis. Journal of Parasitology 78(3): 518-523

Teppema, J.S., Robinson, J.E., and E.J. Ruitenberg. 1973. Ultrastructural aspects of capsule formation in Trichinella spiralis infection in the rat. Parasitology 66: 291-296

Thienpont, D., Varysarijs, O. and R. Vandesteene. 1974. Anthelmintic and histopathological effects of mebendazole on Trichinella spiralis in the rat. In Trichinellosis . C.W, Kim (ed.). Intext, New York, p. 515-527

Thom, J.R. and N.P. Morris. 1991. Biosynthesis and proteolytic processing of Type XI collagen in embryonic chick sterna. Journal of Biological Chemistry 266(11): 72627296

Timpl R., Rhode H., et al. 1982. Laminin. Methods in Enzymology 82: 831-838

Timpl R. 1984. Immunology of the Collagens. In Extracellular Matrix Biochemistry. K.A. Piez and A.H. Reddi (eds.). Elsevier, New York, p. 159-190

Timpl, R. 1989. Structure and biological activity of basement membrane proteins. European J. Biochem 180: 487-502

Trager, W. 1986. Living together. Plenum Press, New York, p. 467

Trelstad, R.L., and F. Silver. 1981. Matrix Assembly. In Cell Biology of Extracellular Matrix. E. D. Hay (ed.). Plenum Press, New York, P. 199

van der Rest, M., and R. Garrone. 1991. Collagen family of proteins. FASEB Journal 5: 2814-2823 
Vassilatis, D.K., Despommier, D., Misek, D., Polvere, R., Gold, A., and L. Van der Ploeg. 1992. Analysis of a 43-kDa glycoprotein from the intracellular parasitic nematode Trichinella spiralis. Journal of Biological Chemistry 267(26): 18459-18465

Von der Mark, K., Aumailley, M., Wick, G., et al. 1984. Immunochemistry, genuine size and tissue localization of collagen VI. European Journal of Biochemistry 142: 493-502

Vuorio, E. and B. De Crombrugghe. 1990. The family of collagen genes. Annu. Rev. Biochem. 59: 837-872

Wakelin, D. 1992. Immunogenetic and evolutionary influences on the host-parasite relationship. Developmental and Comparative Immunology 16: 345-353

Wang, C.H., and R.G. Bell. 1986. Trichinella spiralis: Newborn larval migration route in rats reexamined. Experimental Parasitology 61: 76-85

Wassom, D.L. 1993. Immunoecological succession in host-parasite communities. Journal of Parasitology 79(4): 483-487

Worthington, C. 1988. Pepsinogen: Pepsin. In Worthington Enzyme Manual. C. Worthington (ed.). Worthington Biochemical Corporation, Freehold, p. 250-253

Wright, K.A. 1979. Trichinella spiralis: an intracellular parasite in the intestinal phase. Journal of Parasitology 65: 441-445

Wright, K.A. and H. Hong. 1989. Trichinella spiralis: The fate of the accessory layer of the cuticle of infective larvae. Experimental Parasitology 68: 105-107

Wright, K.A., Weidman, E., and H. Hong. 1987. The distribution of cells killed by Trichinella spiralis in the muccosal epithelium of two strains of mice. Journal of Parasitology 73: 935-939

Yamada, S., Buffinger, N., Dimario, J., and R.S. Strohman. 1989. FGF is stored in fiber extracellular matrix and plays a role in regulating muscle hypertrophy. Med. Sci. Sport and Exercise 21(5): 173-180

Yurchenco, P. and J. Schittny. 1990. Molecular architecture of basement membranes. FASEB Journal 4: 1577-1590 